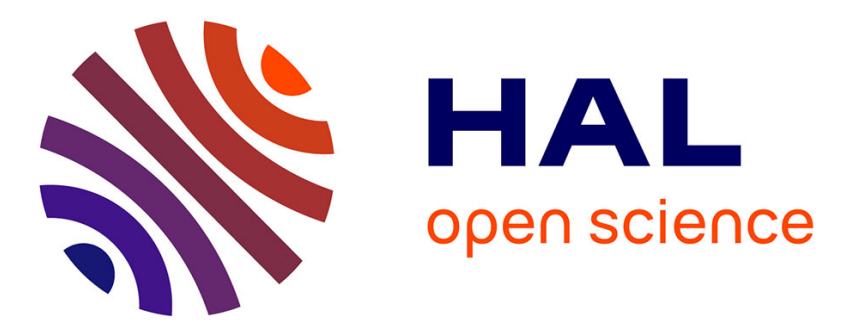

\title{
Lipids in benthic diatoms: A new suitable screening procedure
}

Eva Cointet, Gaëtane Wielgosz-Collin, Vona Méléder, Olivier Gonçalves

\section{To cite this version:}

Eva Cointet, Gaëtane Wielgosz-Collin, Vona Méléder, Olivier Gonçalves. Lipids in benthic diatoms: A new suitable screening procedure. Algal Research - Biomass, Biofuels and Bioproducts, 2019, 39, pp.101425. 10.1016/j.algal.2019.101425 . hal-02333689

\section{HAL Id: hal-02333689 \\ https://hal.science/hal-02333689}

Submitted on 22 Oct 2021

HAL is a multi-disciplinary open access archive for the deposit and dissemination of scientific research documents, whether they are published or not. The documents may come from teaching and research institutions in France or abroad, or from public or private research centers.
L'archive ouverte pluridisciplinaire HAL, est destinée au dépôt et à la diffusion de documents scientifiques de niveau recherche, publiés ou non, émanant des établissements d'enseignement et de recherche français ou étrangers, des laboratoires publics ou privés.

\section{다(1) $\$$}

Distributed under a Creative Commons Attribution - NonCommercial| 4.0 International 


\section{Lipids in benthic diatoms: a new suitable screening procedure}

2 Short title: Screening and rapid selection of lipid rich benthic diatoms

3 Eva Cointet ${ }^{1}$, Gaëtane Wielgosz-Collin ${ }^{1}$, Vona Méléder ${ }^{1}$, Olivier Gonçalves ${ }^{2} \square$

$4{ }^{1}$ Université de Nantes, Laboratoire Mer Molécules Santé, EA 21 60, BP 92208, 44322 Nantes,

5 France

$6 \quad{ }^{2}$ Université de Nantes, GEPEA, UMR CNRS-6144, Bât.CRTT, 37 Boulevard de l'Université, 7 BP406, F-44602 Saint-Nazaire Cedex, France

\section{Abstract}

The selection of suitable and indigenous microalgae species is a fundamental requirement in developing added-value bioactive compounds recoverable in the food, health, and cosmetics

11 markets. In this work, an integrated screening approach was developed to characterize the lipid rate of 33 diatom species (including 15 species studied for the first time) belonging to 16 genera from the Nantes Culture Collection, with the main objective of discovering bioactive lipid producers. For that purpose, a simple reliable method for establishing growth kinetics of strains and semi-quantitative analysis of lipid rates was developed. Growth kinetics measurements were achieved by daily minimal measurement fluorescence (F0) whereas lipid rate analyses were performed by high-throughput Fourier Transform Infrared spectroscopy on entire cells and lipid extracts. Results indicated that the method could be used directly on entire cells in spite of the presence of silica for the FTIR approach (due to frustule). The total lipid rate was species-dependant and ranged from $3.7 \%$ to $30.5 \%$ DW. Six strains out of 33 were found to

21 present a higher total lipid rate superior to $15 \% \mathrm{DW}$, and 11 showed medium lipid rates ranging 22 from $10 \%$ to $15 \%$ DW. The results revealed that five diatom species i.e. Amphora sp. NCC169, Nitzschia sp. NCC109, Nitzschia alexandrina NCC33, Opephora sp NCC366 and Staurosira sp. NCC182 presented interesting growth capabilities and should be further investigated as potential sources for their original lipid rate. 
28 Keywords: FTIR spectroscopy, growth kinetics, benthic Diatoms, lipid rate, bioactive fatty

29 acids.

31 Highlights

- Minimal fluorescence measurement characterized growth capabilities

- FTIR spectroscopy on whole cells characterized lipid rates

- Lipid rates of 15 strains were highlighted for the first time

- Five strains of benthic diatoms were selected for furthers biotechnology applications

${ }^{*}$ Corresponding authors

isep:Email: olivier.goncalves@univ-nantes.fr (Olivier Gonçalves), eva.cointet@univnantes.fr (Eva Cointet), vona.meleder@univ-nantes.fr (Vona Méléder), Gaetane.WielgoszCollin@univ-nantes.fr (Gaëtane Wielgosz-Collin).

iscepiPreprint submitted to Algal Research September 09, 2018

\section{Conflict of interest}

44 The authors declare that there is no conflict of interest. No conflicts, informed consent, human 45 or animal rights are applicable to this work.

\section{Author's contribution}

Eva Cointet, Gaëtane Wielgosz-Collin, Vona Méléder and Olivier Gonçalves designed and

49 supervised the research. Eva Cointet, Gaëtane Wielgosz-Collin, Vona Méléder and Olivier

50 Gonçalves conducted experiments. Eva Cointet, Gaëtane Wielgosz-Collin, Vona Méléder and 
51 Olivier Gonçalves analyzed and interpreted the data and drafted the manuscript. Eva Cointet,

52 Gaëtane Wielgosz-Collin, Vona Méléder and Olivier Gonçalves critically reviewed the 53 manuscript. All authors read and approved the final version of the manuscript.

54

\section{Acknowledgements}

56 This work was supported by the regional Atlantic Microalgae research program (AMI), funded 57 by the Pays de la Loire region. We also express our sincere thanks to GEPEA staff in particular 58 Remy Coat and Delphine Kucma for support and advice on the FTIR spectrometer. 


\section{Abbreviation}

60 ATR: Attenuated Total Reflectance

61 AW: Ash weight

62 DW: Dry weight

63 DHA: Docosahexaenoic acid

64 EPA: Eicosapentaenoic acid

65 FA: Fatty acid

66 F0: Minimum chlorophyll fluorescence

67 HTSXT-FTIR: Fourier-transform infrared spectroscopy high-throughput screening extension

68 LED: Late exponential day

69 LED biomass: Biomass corresponding to culture harvest days

70 MUFA: Monounsaturated fatty acid

71 NCC: Nantes Culture Collection

72 NDVI: Normalized Difference Vegetation Index

73 N: Nitrogen

74 PFD: Photon flux density

75 PAM: Pulse amplitude modulation

76 PAR: Photosynthetically active radiation

77 PUFA: Polyunsaturated fatty acid

$78 \rho:$ Reflectance

79 SD : Standard deviation

$80 \quad$ Si : Silica

81 SFA: Saturated fatty acid

82 TAG: Triacylglycerol

$83 \mu$ max: Maximum growth rate 


\section{Introduction}

In the last two decades, a large body of research has focused on finding new strains of microalgae capable of producing high lipid content for a wide range of applications including pharmaceutical, cosmetics and alternative biofuels [1-4]. In the kingdom of microalgae, diatoms are very accessible resources, since they are ubiquitously found in most aquatic environments (rivers, oceans, coastal areas). They constitute a unicellular eukaryotic group with a typical species-specific siliceous cell wall (also known as frustule). They present different life-forms that could be benthic (microphytobenthos) or planktonic (phytoplankton). Marine diatoms can grow quickly and store large amounts of lipids [5]. Their lipids are mainly composed of a neutral fraction with traces of sterols and polar lipids [6]. Neutral lipids constitute the reserve fraction, with triacylglycerol (TAG) accounting for more than $60 \%$ of the total lipids [7]. Their PUFAs are mainly composed of eicosapentaenoic acid (EPA, C20:5 n-3) [8] but some strains were also found to present docosahexaenoic acid (DHA, C22:6 n - 3) [9]. The biosynthesis of the lipids varies within the different diatom species, their growth stages, and environmental parameters [10,11]. Previous studies [5-9] have demonstrated their ability for lipid production, more specifically for the PUFA fraction (DHA and EPA), recognized for its broad spectrum bioactivities (anti-carcinogenic, immune modulation, anti-diabetic, antiobesity and anti-thrombotic properties) [12]. Unfortunately, the Diatoms group is poorly studied and constitutes therefore an underexploited resource [13] even if the number of their genera and species is estimated to be between 250 and 100,000 [14]. Bioprospecting efforts should therefore be encouraged in order to assess this potential. Basically, bioprospecting would be achieved if the identified microalgae could be exploited at an industrial scale for their biomass or their high value lipid compounds [1]. Therefore, during the screening approach, specific focus should be performed on the efficient identification of the appropriate microalgae strains, i.e. those characterized by high productivity (biomass and lipids), high resistance to 
110 contamination and high tolerance to a wide range of environmental parameters [15-18]. Native

111 species adapt to local environmental changes and should be thus resilient and competitive 112 enough regarding these criteria. However, systematic estimation of the growth rates requires a

113 time-consuming series of measurements in order to estimate biomass evolution. The cell count 114 approach is among the most widely used. Alternatively, other parameters could be measured as 115 proxy for the cell numbers, if it could be shown to be linearly correlated. Typical proxy 116 measurements are in vivo fluorescence [19], optical density and biomass direct estimation (such 117 as dry weight, pigment content) [20] and in vivo or in solvent spectroscopy [21]. The 118 concentrations of protein, carbohydrates and lipids in cultures could also be used as proxy 119 measures depending of the robustness of their linear relationship with either cell numbers or 120 biomass. Finally, the cell number is recognized as being a robust reference method if "counting 121 methods" are easily available and could be applied to a given biological system. Only in vivo 122 fluorescence and spectroscopy seem to be faster than cell counting and are easy to use. For 123 these reasons, one of the objectives of this study is to test both techniques as an alternative to 124 counting in the screening process. Conventional methods used for lipid determination, 125 systematically require solvent extraction and gravimetric determination. These methods are 126 time consuming, need extensive manipulations, use high amounts of biomass (10-15 mg [22]) 127 and have a low throughput screening rates. Consequently, a faster measurement of the lipid 128 content is needed [23]. As for counting methods, alternative approaches exist, that can be 129 roughly classified into invasive and non-invasive techniques. Fluorescent based technologies 130 are the most commonly used and require fluorescent dyes like Bodipy. However, it is an indirect 131 measure that has several issues such as sample preparation before staining, careful choice of 132 dye especially in microalgae due to the presence of chlorophylls within chloroplasts, leading to 133 non-quantitative information [24]. Vibrational spectroscopy such as Raman [25] could be a 134 good alternative for investigating lipid content since it can image and chemically identify the 
135 lipids without labelling. However, autofluorescence signals from the chloroplast will 136 overwhelm the Raman signal. Increasing the acquisition time or incident power can solve this 137 issue, although irreversible photo damage may result, leading to loss of the semi-quantitative

138 information, limiting therefore its use in the context of high-throughput screening. Infrared 139 spectroscopy has advantages over the above techniques, since it limits photodamage, is not 140 influenced by autofluorescence, and presents robust systems such as high-throughput screening 141 for chemical spectra acquisition for large quantities of samples. Coat et al. demonstrated [26] 142 that it was robust and sensitive enough to quantify the lipids and that directly on entire 143 microalgae cells. The second objective of this study was to test this technique as an alternative 144 to gravimetric determination of lipid content.

145 In the present work, we propose to explore the potential for original lipid sourcing of the benthic 146 diatoms hosted in the Nantes Culture Collection (NCC) bank. First - to identify the NCC strains 147 that could potentially produce interesting fatty acids - a bibliographic inventory of current and 148 past knowledge of the principal genus and species hosted in the NCC bank was conducted. It 149 focused on the families of molecules with high added value for pharmacology, health, nutrition, 150 and cosmetics such as PUFAs, taking also into account the influence of cultural conditions $151[27,28]$. The selected species were then, investigated to gain basic knowledge on their biological 152 characteristics, to highlight their chemo diversity (in terms of protein, carbohydrates, silica and 153 lipid rates), and finally on their potential for high-value fatty acid molecule biosynthesis. To 154 select the most promising NCC strains, an original workflow was developed, integrating 155 different steps including the analysis of the NCC strain growth and their rapid biochemical 156 profiling through HTSXT-FTIR. The results obtained in the present study are discussed 157 hereafter. 


\section{Material and methods}

\subsection{Strains cultivation}

160 Diatom strains from the NCC were selected and cultivated in $250 \mathrm{~mL}$ Erlenmeyer flasks filled

161 with $150 \mathrm{~mL}$ of $\mathrm{F} / 2$ culture medium, enriched in silica using $0.47 \mu \mathrm{m}$ filtered natural sea water

$162[29,30]$. Vitamins and carbonates were added before autoclave sterilization (Autoclave Vertical

163 Lequeux AUV 100L), salinity was adjusted at 28 and $\mathrm{pH}$ was fixed at 7.8 to reduce nutrient

164 precipitation. Inoculation of each strain was performed from the stock cultures with an initial

165 concentration of 30000 cells. $\mathrm{mL}^{-1}$. The diatom strains were thus grown at $16^{\circ} \mathrm{C}$ with a photon

166 flux density (PFD) of $127 \mu \mathrm{mol}$ photons $\mathrm{m}^{-2} \mathrm{~s}^{-1}$ provided under continuous light to the bottom

167 of flasks by flat led pannel (LP EPURE-Chateaugiron, France).

\subsection{Growth parameter estimations}

169 To retrieve the growth parameters on the screened strains, the growth rate $\left(\mu \max\right.$ in day $\left.{ }^{-1}\right)$ and

170 the end of the exponential phase were identified. The growth rate identifies the faster growing

171 strains. The end of the exponential phase, known to be the period of lipid accumulation [31],

172 identifies the harvest day for lipid analyses. These parameters were retrieved using daily

173 biomass estimation. All erlen flasks and stir bars were autoclaved. Before sampling, flasks were

174 agitated by magnetic stirring for 2 minutes allowing cell and nutrient homogenization and 175 aggregate destruction.

176 Alternative techniques were tested to replace the cell counting by hemocytometer (here

177 Neubauer; $n \geq 300$ ) which is a time-consuming technique.,

178 - Minimum chlorophyll fluorescence measurement (F0) by fluorometry PAM (Water-PAM,

179 Waltz, Germany). This parameter, proportional to Chl $a$ content, was used as a proxy of the

180 vegetal biomass [32]. Measurements were made directly on the microalgal suspension. 
- Reflectance ( $\rho$ ) of the cells by spectroradiometry (Jaz, Ocean Optics, USA) in the PAR domain

182 (400-700 nm). Reflectance values were used to calculate the Normalized Difference Vegetation

183 Index (NDVI) following the equation. (1), known to be proportional to Chl $a$ content and used

184 as a biomass proxy [21]. Measurements were made on filtered microalgae using CML

185 microfiber filters with a $25 \mathrm{~mm}$ diameter and a $0.7 \mu \mathrm{m}$ pore diameter and a $25 \mathrm{~mm}$ Whatman

186 filter funnel.

187

$$
N D V I=\frac{\lambda 750-\lambda 675}{\lambda 750+\lambda 675}
$$

With $\lambda$ 750: maximal reflectance wavelength, and $\lambda 675$ : Chl $a$ absorption wavelength

190 Daily measurements were performed on each sample of culture to follow the growth kinetics

191 (at the beginning of the growth phase and during three days, between $3 \mathrm{~mL}$ and $5 \mathrm{~mL}$ of cultures

192 were sampled, and then $2 \mathrm{~mL}$ until the end of the growth). To extract and compare the growth

193 parameters from the alternative techniques and the cell count approach, the Gompertz model

194 [33] was used to fit the growth data (equation. 2) using MATLAB software. It consisted of a

195 latency phase followed by an exponential phase and a stabilization of the curve at its maximum 196 phase.

$$
f(x)=A \times e^{-e\left(\mu \max \times \frac{e^{1}}{A} \times(\lambda-x)+1\right)}
$$

198 With A: maximum cell concentration in the natural logarithm of the biomass (number of cells.

$199 \mathrm{~mL}^{-1}, \mathrm{~F} 0$ or NDVI); $\mu$ max: Maximum growth rate $\left(\right.$ day $\left.^{-1}\right) ; \lambda$ : Latency (days).

200 The $A$ parameter allows calculation of the biomass (LED biomass) obtained at the late exponential

201 day (LED) (equation. 3). This corresponded to the harvest day for the lipid analyses.

$$
L E D_{\text {biomass }}=\exp (A+\log (B \min ))
$$

203 With Bmin = Initial biomass (number of cells.mL ${ }^{-1}, \mathrm{~F} 0$ or NDVI); $L E D_{\text {biomass }}=$ biomass of the 204 late exponential day (cell.mL ${ }^{-1}, \mathrm{~F} 0$ or NDVI) 
The comparison of the three thechniques, and the selection of the fastest one to estimate the growth parameters was done using a panel of 6 very different strains, chosen for their different growth kinetics and their different morphology (aggregate of cells, cells in chains or solitary cells) : Amphora sp. 1 NCC260, Entomoneis sp. 1 NCC350, Entomoneis sp. 6 NCC335, Entomoneis paludosa NCC18.2, Extubocellulus cribriger NCC229 and Navicula sp. 2 NCC226.

\subsection{Diatom strain characterisation}

At the end of the exponential phase (LED), when the cells were harvested for HTSXT-FTIR analyses (see §2.4), several analysis were perforemd to collect more information about the 215 strains:

216 - the cell length and the width were estimated using the image of light microscopy (OLYMPUS 217 CH40, $\times 400 ; n=150)$.

218 - the dry weight (DW) of the biomass was estimated by filtering $150 \mathrm{~mL}$ of algal suspension 219 through a microfiber filter, Whatman $47 \mathrm{~mm}$ diameter, $0.7 \mu \mathrm{m}$ pore. The filters containing the 220 cells were washed using $10 \mathrm{~mL}$ of ammonium formiate (3\%) to the remove salt. The wet filters 221 were frozen at $-80^{\circ} \mathrm{C}$ and freeze-dried under a vacuum. DW (g.L $\left.\mathrm{L}^{-1}\right)$ and $\mu \max \left(\right.$ day $\left.^{-1}\right)$ were then used to estimate the strain productitivty (Px) in $\mathrm{g} . \mathrm{L}^{-1}$.day ${ }^{-1}$ (equation. 4).

$$
P x=\mu \max \times D W
$$

224 - the strains total lipid rate was assessed by gravimetric assay, to compare it to the infrared semi225 quantitative measurments (HTSXT-FTIR, see $\S 2.4$ ). Biomass filtered, washed and freeze-dried 226 for dry weight estimation were used for lipid content estimation. The filters were macerated in 227 flasks using $100 \mathrm{~mL}$ of solvent per gram of biomass (dichloromethane-methanol (1:1 V/V)) 228 [34]. Maceration at ambient temperature was performed for $24 \mathrm{H}$ on a vibrating tray (Edmund 229 Bühler GmbH, SM-30). After maceration, the mixture was filtered on pleated filters, $190 \mathrm{~mm}$ 230 diameter, $10 \mu \mathrm{m}$ pore, to remove the filter debris and the silica fragments. The filtrates were 
transferred into a separatory funnel with $20 \mathrm{~mL}$ of distilled water and shaken for $5 \mathrm{~min}$. The

232 lipid fraction (organic phase) was then separated from the separatory funnel, dried using an 233 anhydrous sodium sulfate salt, filtered, evaporated and weighed to obtain the crude lipid extract 234 (CLE) value. Total lipid rate (TLR) was finally expressed in \% of the DW (equation. 5).

$$
T L R=\frac{C L E}{D W} \times 100
$$

- the silica content of the cells was also determined to ensure the normalization of the FTIR semi-quantitative results (see $\S 2.4$ ). Cultures were harvested by filtering new $150 \mathrm{~mL}$ of the algal suspension using the same recovery cell procedure used for dry weight estimation. Filters were then freeze-dried, weighed (DW) and heated at $400^{\circ} \mathrm{C}$ for four hours in a muffle oven and weighed (AW) and the silica proportion evaluated in \% of DW by equation. 6 :

$$
\text { Silica content }=\frac{A W}{D W} \times 100
$$

\subsection{Molecular profiles measured by infrared spectroscopy}

The FTIR spectra acquisition on entire cells was performed according to Coat et al. 2014 recommendations [26]. It consisted in concentrating the cells up to $10^{6}-10^{8}$ cells.mL $\mathrm{m}^{-1}$ by centrifugation (10 000g for $5 \mathrm{~min}$ ) using Sigma 3K30 centrifuge. The supernatant was removed, and the pellet resuspended in an ammonium formiate isotonic solution $\left(68 \mathrm{~g} . \mathrm{L}^{-1}\right)$. This process was repeated twice to wash out the cells from the growth medium in order to avoid medium contribution on the FTIR spectra. The cells were thus resuspended in $1 \mathrm{~mL}$ in an isotonic solution. Ammonium formiate solution prevents cell lyses during washing [35]. For the FTIR spectra acquisition, a Bruker tensor 27 FTIR spectrometer equipped with a HTSXT plate reader 251 module coupled to OpusLab v 7.0.122 software (Bruker Optics, Germany) was used. Rinsed cell aliquots of $5 \mu \mathrm{L}$ were deposited on a 384 well microplate, void-dried in a vacuum desiccator for at least 24 hours. FTIR spectra were then recorded in transmission mode directly on the 
255 invasive on intact diatom cells, their biochemical signatures expressed in term of total lipids, 256 total proteins and total carbohydrates superimposed partially with the silica signal of the diatom 257 frustul. To confirm the whole cells FTIR spectra results, estimation of the lipid rate was also 258 performed on crude lipid extract, using attenuated total reflectance sampling system (ATR), 259 that was more suitable forcrude organic extracts. For the acquisition of the ATR spectra, $10 \mu \mathrm{L}$ 260 of crude lipid extract (see \$2.3. [34]) were deposited directly on the Bruker tensor 27 FTIR 261 spectrometer lens. The absorbance spectra were all collected between $4000 \mathrm{~cm}^{-1}$ and $700 \mathrm{~cm}^{-1}$ 262 with 30 scans and averaged. The spectra were analyzed by relatively straightforward methods 263 such as peak ratios or integral ratios [36]. The lipid signature was associated to the $\mathrm{CH}_{2}-\mathrm{CH}_{3}$ 264 signal $\left(\sim 3000-2800 \mathrm{~cm}^{-1}\right)$ and the ester bond $(\mathrm{Eb})$ signal $\left(\sim 1740 \mathrm{~cm}^{-1}\right)$. The carbohydrate 265 signature was associated to the C-O-C signal of the polysaccharides $\left(\sim 1200-900 \mathrm{~cm}^{-1}\right)$ [37]. The 266 protein signature was associated to the amide II band $\left(\sim 1540 \mathrm{~cm}^{-1}\right)$ of the $\mathrm{N}-\mathrm{H}$ of the amides associated to the proteins. The silica signature was associated to the Si-O signal of the silicate 268 frustule $\left(\sim 1068 \mathrm{~cm}^{-1}\right)$ [38]. To estimate the relative content of the lipids, carbohydrates and 269 proteins, their respective peak heights (i.e. ester bond $+\left(\mathrm{CH}_{2}+\mathrm{CH}_{3}\right), \sim 1159 \mathrm{~cm}^{-1}$ and amide II) 270 were standardized to the silica peak [39]. (equation 7). For the crude lipid extract spectra, the 271 ratio used for that purpose was the ester bond and the $\mathrm{CH}_{2}+\mathrm{CH}_{3}$ signals standardized with the total spectrum area (equation 8). FTIR and ATR ratio were expressed in arbitrary units 273 abundance (a.u).

$$
\text { FTIR }=\frac{\text { Peak height }(S)}{\text { Silica peak high }}
$$

$$
\mathrm{S}=\text { lipids }\left(\mathrm{eb}+\left(\mathrm{CH}_{2}+\mathrm{CH}_{3}\right)\right) \text { or carbohydrates }\left(\sim 1159 \mathrm{~cm}^{-1}\right) \text { or amide II }\left(\sim 1540 \mathrm{~cm}^{-1}\right)
$$

$$
\mathrm{ATR}=\frac{\text { Peak area }\left(\text { eb+CH}+\mathrm{CH}_{2}+\mathrm{CH} 3\right)}{\text { Total spectra area }}
$$




\subsection{Data processing}

278 The Pearson product-moment correlation was carried out to test the positive correlation between

279 the growth curves obtained with the cell count $\left(\right.$ Cells. $\left.\mathrm{mL}^{-1}\right)$, fluorescence $(\mathrm{F} 0)$ and reflectance 280 (NDVI).

281 Comparison of the growth rate and LED estimated from the three techniques for the selected species were performed using ANOVA when the data presented normal distribution or the Kruskal - Wallis test when the data distribution was not normal. It was systematically followed

284 by the Tuckey post hoc test. The ANOVA was also performed on the growth rate $(\mu \max )$, production (Px) and lipid rate (TLR) results to identify the strains with the highest performance. A multivariate correspondence analysis was performed on the FTIR ratio normalized by silica for lipids, protein and carbohydrates to assess the dispersion of the biochemical information across the screened species and to identify if strains could be classified according to this information. This method was chosen since it analyzes binary, ordinal and nominal data without distributional assumptions (unlike traditional multivariate techniques) and also to preserve the categorical nature of the variables. The correspondence analysis provided a unique graphical

292 display showing how the variable response categories were related [40].

The Pearson product-moment correlation was used to test the correlation between the

294 calculation methods using the FTIR spectra semi-quantitative information with the total lipid 295 quantification reference method (the gravimetric approach). The Pearson product-moment correlation and the comparison of the growth parameters were carried out using SigmaStat 3.1 software. The Past3 software was used for the correspondence analysis approach. All 298 experiments were performed in triplicate.

299 Finally, all the information and tests were combined and used for the validation of the screening 300 methodology to characterize the diatom strains of the NCC and the selection of candidates 301 presenting the best potential in terms of growth capabilities and lipid rates. 


\section{Results}

\subsection{Determination of the growth parameters}

304 The latency, exponential and stationnary phases were observable whatever the technique used 305 to establish the growth curve for the 6 strains selected for their different kinetic behaviour (Fig. 1). Moreover, the cell count, NDVI and F0 data were all correlated (Tab.1) confirming the same

307 growth pattern. Cell count and NDVI were positively correlated $(p<0.001)$ as cell count and F0 $308(p<0.001)$. R values for the NDVI varied from 0.70 to 0.90 and for F0 measurements from 0.60 309 to 0.93.
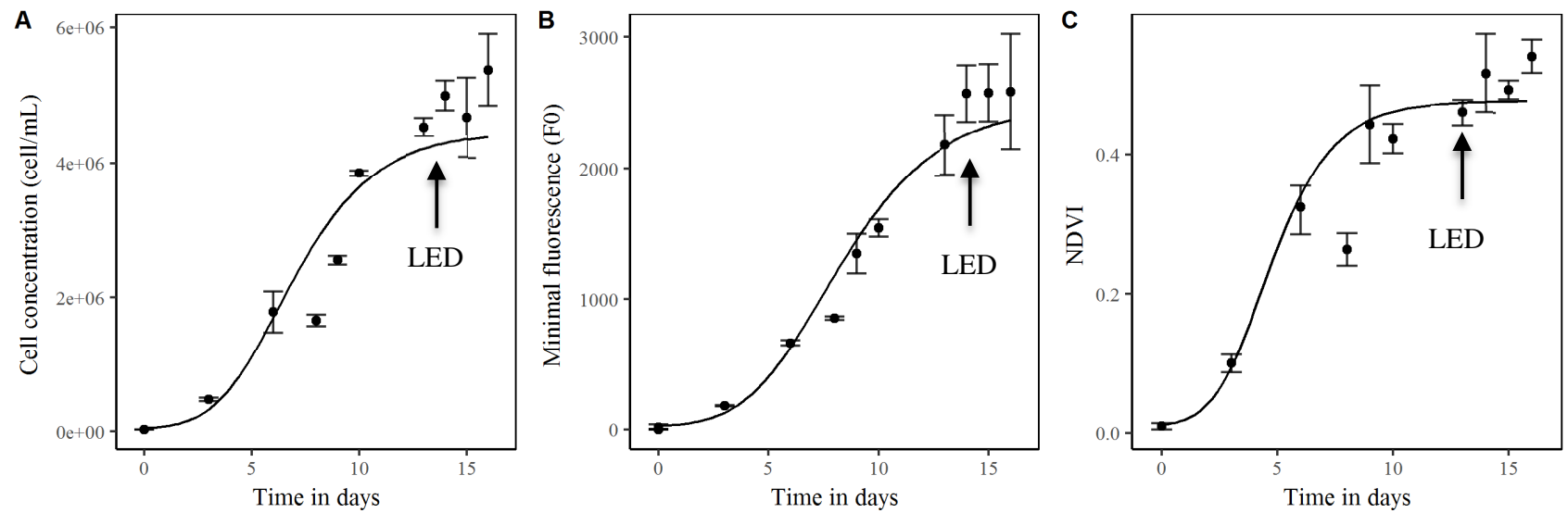

310 Figure1. Example of growth curves measured for Amphora sp 1 NCC260 by (A) cell count,

311 (B) fluorometry PAM (F0) and (C) radiometry (NDVI). Points corresponding to cell

312 concentration according to time. Line curves corresponding to the Gompertz model fitted to

313 cell concentration as a function of time. $n=3$, vertical bar $=$ SD. The arrows indicate the late exponential day estimated by the Gompertz model. 
317 Table 1. Pearson product correlation between radiometry (NDVI) and cell count and

318 fluorometry PAM (F0) and cell count. Correlation was significant ( $\mathrm{p}<0.001)$

\begin{tabular}{ccc}
\hline Species & NDVI & F0 \\
\hline Amphora sp. 1 NCC260 & 0.90 & 0.93 \\
Entomoneis paludosa NCC18.2 & 0.86 & 0.82 \\
Entomoneis sp. 1 NCC335 & 0.86 & 0.81 \\
Entomoneis sp. 6 NCC350 & 0.80 & 0.60 \\
Extubocellulus cf cribriger NCC229 & 0.70 & 0.90 \\
Navicula sp. 2 NCC226 & 0.80 & 0.78 \\
\hline
\end{tabular}

320 There were no significant differences $(p>0.05)$ between the technique used to estimate the 321 growth rate $(\mu \max )$ and the late exponential day (LED) for the six tested species, except for the $322 \mu$ max value estimated for Entomoneis paludosa (Tab. 2). For example, Amphora sp. 1 reached 323 the late exponential phase at the day c.a. 13 (LED, Fig. 1, Tab. 2) with a mean $\mu$ max of c.a. 3240.81 (Tab. 2). At this time, the maximum biomass was reached by the cell count indicator with $3254.5 \pm 0.2 \times 10^{6}$ cells.mL ${ }^{-1}$ by PAM fluorometry with F0 values $2785 \pm 609$, and by radiometry 326 with NDVI reaching $0.47 \pm 0.05$. Because the fluorimetry is used extensively for the 327 measurement of extracted Chl $a$, for the estimation of the phytoplankton Chl $a$ in vivo $[19,41]$ 328 and do not need filtration of high amounts of culture (contrary to NDVI), it was selected as an 329 fast and reliable alternative approach to the cell count to determine the growth rates of all 330 selected diatom strains in this study. Regarding Entomoneis paludosa, a new experiment using 331 only PAM measurments, in the same culture conditions but without counting and NDVI 332 estimation were conducted. $\mu$ max values obtained were $0.52,0.55,0.55$, leading to an average 333 value of $0.54 \pm 0.016$. A second statistical test performed on these new data concluded no 334 significant difference for $\mu \max$ and $\operatorname{LED}(p=0.47)$.

335 Table 2. Values of the growth parameters (maximum growth rate, $\mu \max \left(\mathrm{in}^{-1}\right.$ ) and late 336 exponential day, LED (in days)) retreived from the Gompertz model using six species employed 337 for the comparison of the cell count approach with two alternative techniques: Fluorometry 
338 PAM and radiometry. The calculated $\mathrm{P}$ value corresponded to the ANOVA test except for the

339 (*) values that were obtained using the Kruskal-Wallis test. $\mathrm{N}=3$, independent measurements,

$340 \pm$ SD.

\begin{tabular}{|c|c|c|c|c|c|}
\hline Species & Techniques & $\mu \max \left(\right.$ day $\left.^{-1}\right)$ & LED (day) & $\mathrm{P}$ value $(\mu \max )$ & P Value (LED) \\
\hline \multirow{3}{*}{$\begin{array}{c}\text { Amphora sp. } 1 \\
\text { NCC } 260\end{array}$} & Cell count & $0.76 \pm 0.10$ & $13 \pm 1$ & \multirow{3}{*}{$\mathrm{P}=0.8$} & \multirow{3}{*}{$\mathrm{P}=0.16^{*}$} \\
\hline & Pam & $0.78 \pm 0.30$ & $14 \pm 1$ & & \\
\hline & Spectroradiometer & $0.88 \pm 0.25$ & $12 \pm 2$ & & \\
\hline \multirow{3}{*}{$\begin{array}{c}\text { Entomoneis } \\
\text { paludosa } \\
\text { NCC18.2 }\end{array}$} & Cell count & $0.50 \pm 0.03$ & $12 \pm 1$ & \multirow{3}{*}{$\mathrm{P} \leq 0.05^{1}$} & \multirow{3}{*}{$\mathrm{P}=0.07 *$} \\
\hline & Pam & $0.95 \pm 0.23^{1}$ & $10 \pm 0$ & & \\
\hline & Spectroradiometer & $0.47 \pm 0.01$ & $10 \pm 0$ & & \\
\hline \multirow{2}{*}{$\begin{array}{l}\text { Entomoneis } \\
\text { sp. } 6\end{array}$} & Cell count & $0.53 \pm 0.10$ & $14 \pm 1$ & \multirow{3}{*}{$\mathrm{P}=0.27$} & \multirow{3}{*}{$\mathrm{P}=0.14 *$} \\
\hline & Pam & $0.54 \pm 0.12$ & $12 \pm 1$ & & \\
\hline NCC335 & Spectroradiometer & $0.32 \pm 0.14$ & $12 \pm 2$ & & \\
\hline \multirow{3}{*}{$\begin{array}{c}\text { Entomoneis } \\
\text { sp. } 1 \\
\text { NCC } 350\end{array}$} & Cell count & $0.24 \pm 0.01$ & $16 \pm 2$ & \multirow{3}{*}{$\mathrm{P}=0.29$} & \multirow{3}{*}{$\mathrm{P}=0.09$} \\
\hline & Pam & $0.37 \pm 0.12$ & $14 \pm 1$ & & \\
\hline & Spectroradiometer & $0.35 \pm 0.06$ & $14 \pm 1$ & & \\
\hline \multirow{3}{*}{$\begin{array}{c}\text { Extubocellulus } \\
\text { cf cribriger } \\
\text { NCC } 229\end{array}$} & Cell count & $0.68 \pm 0.04$ & $14 \pm 1$ & \multirow{3}{*}{$\mathrm{P}=0.10$} & \multirow{3}{*}{$\mathrm{P}=0.14$} \\
\hline & Pam & $0.81 \pm 0.01$ & $9 \pm 0$ & & \\
\hline & Spectroradiometer & $0.83 \pm 0.07$ & $10 \pm 3$ & & \\
\hline \multirow{3}{*}{$\begin{array}{l}\text { Navicula sp. } 2 \\
\text { NCC } 226\end{array}$} & Cell count & $0.91 \pm 0.04$ & $8 \pm 0$ & \multirow{3}{*}{$\mathrm{P}=0.42^{*}$} & \multirow{3}{*}{$\mathrm{P}=0.78^{*}$} \\
\hline & Pam & $1.02 \pm 0.23$ & $8 \pm 2$ & & \\
\hline & Spectroradiometer & $0.87 \pm 0.02$ & $9 \pm 2$ & & \\
\hline
\end{tabular}

${ }^{1}$ Entomoneis paludosa $\mu$ max value for the second run was 0.54 and associated $\mathrm{P}$ value was 0.47

\subsubsection{Diatom strain characteristics}

343 Among the 68 screened strains, 33 were cultivated successfully and 36 did not grow

344 (supplementary data 1). This information is reported in Tab. 3, (with the NCC reference, the

345 sampling location, the cell size, the LED, the growth rate, the silica content, the DW and lipid 346 rate). Globally the cell length varied from $58 \pm 14 \mu \mathrm{m}$ (Craspedostauros sp. 2 NCC218) to 4.8 $347 \pm 0.7 \mu \mathrm{m}$ (Extubocellulus cf cribriger NCC229). The cell width varied from $22.6 \pm 4.1 \mu \mathrm{m}$

348 (Lithodesmium sp NCC353) to $2.9 \pm 0.4 \mu \mathrm{m}$ (Fallacia sp. 1 NCC303). The end of the 349 exponential phase, corresponding to the harvest day (LED), varied from day 6 for Surirella sp.

3501 NCC270 to day 16 for Craspedostauros britannicus NCC228 and Navicula sp. 1 NCC113 351 (ANOVA, $p<0.001$ ). Three groups were therefore identified depending on their growth rate: 352 group A, included Nitzschia alexandrina NCC33 and Entomoneis sp. 5 NCC302 with 353 respective growth rates of $1.89 \pm 0.10$ and $1.50 \pm 0.18$ day $^{-1}$, group B with 13 species (i.e $40 \%$ 354 of the total number of strain) presented a growth rate ranging from $1.19 \pm 0.08$ to $0.81 \pm 0.09$ 
day $^{-1}$ and group C with 18 species (54\%) had a growth rate below 0.8 day $^{-1}$ with a minimum at $0.22 \pm 0.05$ day $^{-1}$

To ensure the standardization of the FTIR results for inter species comparison purposes, the total silica rate was evaluated for the 33 species. It showed a significant difference (ANOVA, $\mathrm{p}<0.01$ ), where five species (i.e. $15 \%$ of the total number of strains) had a silica content of c.a. $40 \%$ of the dry weight with a maximum of $46.11 \pm 4.58 \%$ for Entomoneis sp 1 NCC 350 . Three species (i.e. $9 \%$ of the total number of strains) presented a silica content of c.a. $23 \%$ of the dry weight with a minimum of $22.9 \pm 2.6 \%$ for Conticriba weissflogii CCMP1336. In the other species, representing more than $75 \%$ of the total number of strains, the differences were not significant (ANOVA, $p=0.055$ ), supporting a stable silica content situated at around $35 \% \mathrm{DW}$. The dry weight (DW) biomass values of the assessed strains ranged from $0.502 \pm 0.039$ g.L $\mathrm{L}^{-1}$ (Craspedostauros britannicus NCC195) to $0.065 \pm 0.001$ g.L.1 (Entomoneis sp. 3 NCC351). For three strains (9\% of the total number of strains) the DW was greater than 0.30 g.L.- . For 27 strains $(81 \%)$ the biomass was greater than 0.10 g.L $\mathrm{L}^{-1}$ but lower than 0.30 g.L $\mathrm{L}^{-1}$. For the three remaining strains $(9 \%)$ the biomass was lower than 0.10 g. $\mathrm{L}^{-1}$.

The lipid rate estimated with the gravimetric method ranged from $30.5 \pm 0.7 \%$ DW (Nitzschia sp. 5 NCC109) to $3.7 \pm 1.1 \%$ DW (Brockmaniella brockmanii NCC161). For three strains (9\%) the lipid rate was greater than $20 \%$ DW. For 14 strains (42\%) the lipid rate was greater than $10 \%$ DW. In the remaining 16 strains (48\%) the lipid rate was lower than $10 \%$ DW. Biomass productivity varied substantially among the tested strains (Fig. 2A) and ranged from $0.36 \pm 0.02 \mathrm{~g} . \mathrm{L}^{-1} \cdot \mathrm{day}^{-1}\left(\right.$ Nitzschia alexandrina NCC33) to $1.4 \pm 0.3 \times 10^{-2} \mathrm{~g} . \mathrm{L}^{-1} \cdot \mathrm{day}^{-1}$ (Entomoneis sp. 3 NCC351). The results were found to be statistically different among those strains (ANOVA, $p<0.001$ ). Finally, the strains were clustered into three groups according to 378 the following parameters (Fig. 2): group 1 with productivity between $0.35 \pm 0.02$ and $0.19 \pm$ 
380 group 3 with lower productivity ranging from $7.5 \pm 0.4 \times 10^{-2}$ to $1.4 \pm 0.3 \times 10^{-2}\left(\mathrm{~g}^{\mathrm{L}} \mathrm{L}^{-1}\right.$.day $\left.{ }^{-1}\right)$.

381 The most productive strains were those exhibiting the highest $\mu$ max associated to the highest 382 DW. But they did not correspond to the richest in terms of total lipid rate (Fig. 2B).

383

384

385 


\begin{tabular}{|c|c|c|c|c|c|c|c|c|c|c|}
\hline \multirow{2}{*}{ Species } & \multirow{2}{*}{$\begin{array}{c}\text { NCC strain } \\
\text { identification }\end{array}$} & \multirow{2}{*}{ Sampling location } & \multicolumn{2}{|c|}{ Cell size $(\mu \mathrm{m})$} & \multirow{2}{*}{$\begin{array}{l}\text { LED } \\
\text { (day) }\end{array}$} & \multirow[t]{2}{*}{$\mu \max$} & \multirow{2}{*}{$\begin{array}{l}\text { Silica content } \\
(\%)\end{array}$} & \multirow{2}{*}{$\begin{array}{c}\text { Biomass } \\
\left(\mathrm{g} . \mathrm{L}^{-1}\right)\end{array}$} & \multirow{2}{*}{$\begin{array}{c}\text { TLR } \\
(\% \mathrm{DW})\end{array}$} & \multirow{2}{*}{ Ref } \\
\hline & & & Length & Width & & & & & & \\
\hline Nitzschia alexandrina & NCC33 & France, $N W$ Atlantic coast & $11.0 \pm 1.2$ & $3.7 \pm 0.4$ & $11 \pm 0$ & $1.89 \pm 0.10$ 年 & A $27.2 \pm 3.8$ & $0.189 \pm 0.004$ & $12.7 \pm 3.2$ & {$[15,42-49]$} \\
\hline Entomoneis sp. 5 & NCC302 & France, $N W$ Atlantic coast & $22.4 \pm 3.5$ & $15.0 \pm 2.2$ & $9 \pm 0$ & $1.50 \pm 0.18$ & $38.9 \pm 0.7$ & $0.132 \pm 0.025$ & $6.9 \pm 2.4$ & {$[50-54]$} \\
\hline Entomoneis sp. 2 & NCC20 & France, $N W$ Atlantic coast & $30.5 \pm 4.6$ & $18.5 \pm 3.2$ & $8 \pm 0$ & $1.19 \pm 0.08$ & $34.3 \pm 2.8$ & $0.244 \pm 0.042$ & $10.3 \pm 2.7$ & {$[50-54]$} \\
\hline Staurosira sp. & NCC182 & France, $N W$ Atlantic coast & $6.9 \pm 1.4$ & $5.5 \pm 1.2$ & $8 \pm 2$ & $1.17 \pm 0.09$ & $28.9 \pm 5.1$ & $0.262 \pm 0.084$ & $25.1 \pm 1.2$ & {$[16]$} \\
\hline Fallacia sp. 1 & NCC303 & Greenland, east coast & $6.4 \pm 0.7$ & $2.9 \pm 0.4$ & $12 \pm 2$ & $1.12 \pm 0.14$ & $37.4 \pm 4.5$ & $0.154 \pm 0.016$ & $14.2 \pm 1.9$ & - \\
\hline Fallacia sp. 2 & NCC304 & Greenland, east coast & $6.4 \pm 0.8$ & $3.1 \pm 0.4$ & $12 \pm 0$ & $1.07 \pm 0.15$ & $31.8 \pm 4.9$ & $0.265 \pm 0.028$ & $9.2 \pm 3.3$ & - \\
\hline Entomoneis sp. 7 & NCC445 & France, $N W$ Atlantic coast & $10.4 \pm 1.5$ & $4.1 \pm 0.7$ & $9 \pm 2$ & $1.02 \pm 0.05$ & $41.4 \pm 2.9$ & $0.122 \pm 0.005$ & $10.2 \pm 2.8$ & [50-54] \\
\hline Entomoneis paludosa & NCC18.1.1 & France, $N W$ Atlantic coast & $18.4 \pm 3.3$ & $10.7 \pm 1.9$ & $11 \pm 1$ & $0.96 \pm 0.03$ & $37.8 \pm 4.0$ & $0.130 \pm 0.016$ & $5.3 \pm 0.3$ & [50-54] \\
\hline Entomoneis sp. 4 & NCC301 & France, $N W$ Atlantic coast & $23.9 \pm 3.4$ & $17.3 \pm 2.2$ & $7 \pm 1$ & $0.92 \pm 0.14$ & $26.7 \pm 3.9$ & $0.171 \pm 0.012$ & $6.7 \pm 1.5$ & {$[50-54]$} \\
\hline Pseudonitzschia americana & PNA06 KER & France, $N W$ Atlantic coast & $6.6 \pm 0.8$ & $4.5 \pm 0.5$ & $9 \pm 2$ & $0.89 \pm 0.09$ & B $36.4 \pm 0.6$ & $0.099 \pm 0.019$ & $5.7 \pm 1.6$ & - \\
\hline Surirella sp. 1 & NCC270 & France, $N W$ Atlantic coast & $6.8 \pm 1.3$ & $5.0 \pm 1.6$ & $6 \pm 1$ & $0.85 \pm 0.31$ & $33.7 \pm 3.5$ & $0.173 \pm 0.033$ & $19.3 \pm 2.8$ & - \\
\hline Navicula sp. 2 & NCC226 & France, $N W$ Atlantic coast & $9.1 \pm 1.3$ & $5.6 \pm 0.7$ & $8 \pm 2$ & $0.82 \pm 0.05$ & $41.4 \pm 1.5$ & $0.131 \pm 0.015$ & $8.7 \pm 2.5$ & {$[15,45,47,49,55,58]$} \\
\hline Opephora sp. 1 & NCC366 & France, $N W$ Atlantic coast & $5.4 \pm 0.8$ & $3.7 \pm 0.8$ & $14 \pm 1$ & $0.82 \pm 0.16$ & $37.8 \pm 8.4$ & $0.233 \pm 0.010$ & $11.5 \pm 3.1$ & - \\
\hline Entomoneis paludosa & NCC18.2.1 & France, $N W$ Atlantic coast & $18.8 \pm 1.8$ & $11.2 \pm 2.5$ & $12 \pm 1$ & $0.81 \pm 0.0 .5$ & $36.0 \pm 3.9$ & $0.150 \pm 0.003$ & $7.3 \pm 1.0$ & {$[50-54]$} \\
\hline Extubocellulus cf cribriger & NCC229 & France, $N W$ Atlantic coast & $4.8 \pm 0.7$ & $3.9 \pm 0.5$ & $9 \pm 0$ & $0.81 \pm 0.09$ & $33.7 \pm 2.3$ & $0.155 \pm 0.003$ & $14.2 \pm 4.8$ & {$[52,59,60]$} \\
\hline Amphora sp. 1 & NCC260 & France, $N W$ Atlantic coast & $9.8 \pm 1.3$ & $3.7 \pm 0.5$ & $13 \pm 0$ & $0.78 \pm 0.30 \uparrow$ & $36.2 \pm 2.6$ & $0.176 \pm 0.041$ & $18.5 \pm 4.2$ & {$[49,55,58,61,62]$} \\
\hline Conticriba weissflogii & CCMP1336 & USA, NE Atlantic coast & $15.6 \pm 2.5$ & $10.8 \pm 1.4$ & $12 \pm 0$ & $0.59 \pm 0.15$ & $22.9 \pm 2.6$ & $0.277 \pm 0.035$ & $7.2 \pm 1.7$ & - \\
\hline Brockmaniella brockmanii & NCC161 & France, $N W$ Atlantic coast & $9.2 \pm 2.4$ & $4.3 \pm 0.6$ & $10 \pm 0$ & $0.58 \pm 0.01$ & $37.5 \pm 0.2$ & $0.185 \pm 0.025$ & $3.7 \pm 1.1$ & - \\
\hline Craspedostauros britannicus & NCC195 & France, $N W$ Atlantic coast & $37.8 \pm 8.8$ & $11.0 \pm 2.2$ & $9 \pm 0$ & $0.53 \pm 0.09$ & $44.7 \pm 0.1$ & $0.502 \pm 0.039$ & $8.2 \pm 1.8$ & - \\
\hline Conticriba weissflogii & NCC133 & Morocco,Oum R'bia estuary & $14.3 \pm 1.7$ & $12.1 \pm 1.7$ & $7 \pm 0$ & $0.53 \pm 0.08$ & $34.6 \pm 1.2$ & $0.181 \pm 0.015$ & $6.4 \pm 0.7$ & - \\
\hline Licmophora sp. 1 & NCC253 & France, $N W$ Atlantic coast & $20.0 \pm 3.9$ & $12.4 \pm 1.6$ & $11 \pm 0$ & $0.51 \pm 0.02$ & $37.8 \pm 5.7$ & $0.161 \pm 0.049$ & $13.5 \pm 1.1$ & - \\
\hline Amphora sp. 2 & NCC169 & France, $N W$ Atlantic coast & $9.0 \pm 1.2$ & $5.8 \pm 1.2$ & $13 \pm 3$ & $0.48 \pm 0.14$ & $33.8 \pm 4.8$ & $0.157 \pm 0.024$ & $16.0 \pm 2.6$ & {$[49,55,58,61,62]$} \\
\hline Craspedostauros sp. 1 & NCC228 & France, $N W$ Atlantic coast & $55 \pm 14$ & $14.9 \pm 4.2$ & $16 \pm 4$ & $0.46 \pm 0.22$ & C $25.2 \pm 0.7$ & $0.384 \pm 0.042$ & $5.6 \pm 1.4$ & - \\
\hline Craspedostauros sp. 2 & NCC218 & France, $N W$ Atlantic coast & $58 \pm 14$ & $13.6 \pm 3.4$ & $12 \pm 0$ & $0.45 \pm 0.18$ & $26.0 \pm 4.1$ & $0.178 \pm 0.047$ & $5.9 \pm 1.4$ & - \\
\hline Cymatosira belgica & NCC208 & France, $N W$ Atlantic coast & $5.6 \pm 0.6$ & $4.7 \pm 0.7$ & $12 \pm 0$ & $0.44 \pm 0.12$ & $35.5 \pm 3.4$ & $0.118 \pm 0.043$ & $14.6 \pm 3.0$ & - \\
\hline Amphora acutiuscula & NCC216 & Viet Nam, South east coast & $10.0 \pm 1.0$ & $5.6 \pm 0.8$ & $11 \pm 0$ & $0.43 \pm 0.07$ & $32.4 \pm 0.7$ & $0.144 \pm 0.041$ & $13.7 \pm 5.1$ & {$[49,55,58,61,62]$} \\
\hline Lithodesmium $s p$ & NCC353 & Australia, Moreton bay & $29.3 \pm 5.4$ & $22.6 \pm 4.1$ & $9 \pm 1$ & $0.43 \pm 0.02$ & $34.1 \pm 6.1$ & $0.129 \pm 0.006$ & $7.1 \pm 2.9$ & - \\
\hline Navicula sp. 1 & NCC113 & Morocco,Oum R'bia estuary & $17.1 \pm 2.9$ & $5.1 \pm 1.2$ & $16 \pm 0$ & $0.42 \pm 0.02$ & $25.0 \pm 1.0$ & $0.168 \pm 0.035$ & $23.1 \pm 6.4$ & {$[15,45,47,49,55,58]$} \\
\hline Entomoneis sp. 6 & NCC335 & France, Mediterranean Sea & $13.9 \pm 1.9$ & $7.7 \pm 1.9$ & $12 \pm 1$ & $0.38 \pm 0.03$ & $36.8 \pm 4.7$ & $0.226 \pm 0.036$ & $3.7 \pm 1.1$ & {$[50-54]$} \\
\hline Entomoneis sp. 1 & NCC350 & France, Mediterranean Sea & $29.0 \pm 4.0$ & $17.5 \pm 2.7$ & $14 \pm 0$ & $0.36 \pm 0.13$ & $46.1 \pm 4.6$ & $0.098 \pm 0.048$ & $8.8 \pm 0.1$ & {$[50-54]$} \\
\hline Craspedostauros britannicus & NCC199 & France, $N W$ Atlantic coast & $31.2 \pm 3.2$ & $8.8 \pm 1.6$ & $12 \pm 2$ & $0.35 \pm 0.14$ & $40.0 \pm 2.9$ & $0.421 \pm 0.053$ & $12.5 \pm 1.2$ & - \\
\hline Nitzschia sp. 5 & NCC109 & France, $N W$ Atlantic coast & $33.1 \pm 4.1$ & $10.1 \pm 1.5$ & $12 \pm 1$ & $0.31 \pm 0.05$ & $23.0 \pm 1.5$ & $0.239 \pm 0.026$ & $30.5 \pm 0.7$ & {$[15,42-49]$} \\
\hline Entomoneis sp. 3 & NCC 351 & France, Mediterranean Sea & $16.6 \pm 3.7$ & $12.3 \pm 3.0$ & $13 \pm 0$ & $0.22 \pm 0.05$ & $38.6 \pm 5.8$ & $0.065 \pm 0.001$ & $13.3 \pm 4.6$ & {$[50-54]$} \\
\hline
\end{tabular}




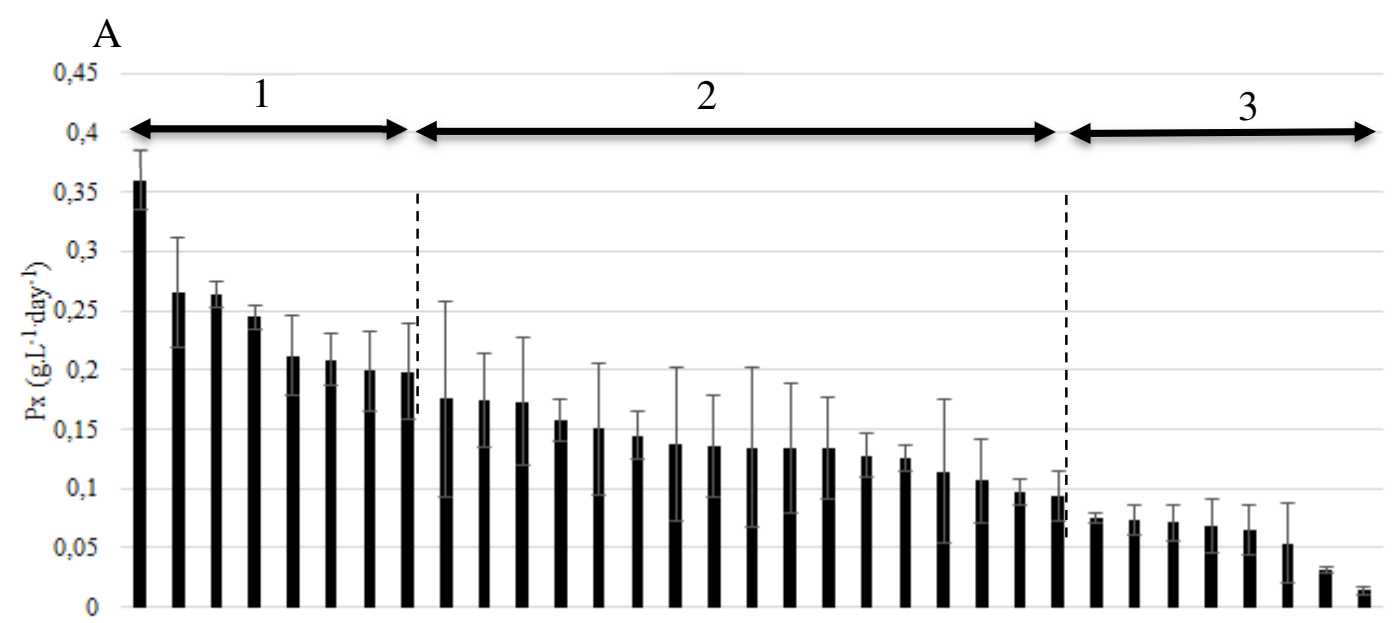

B
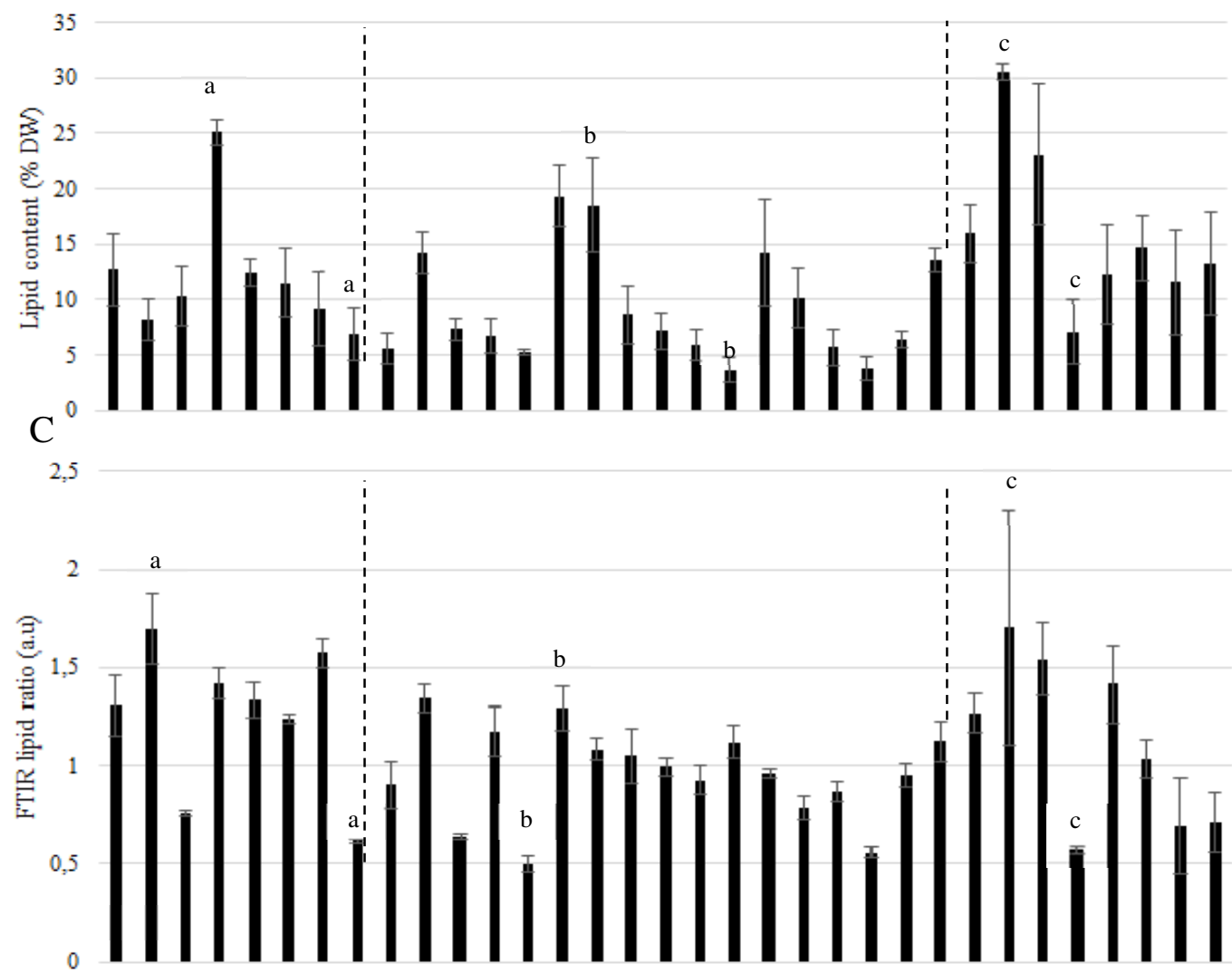

D 70

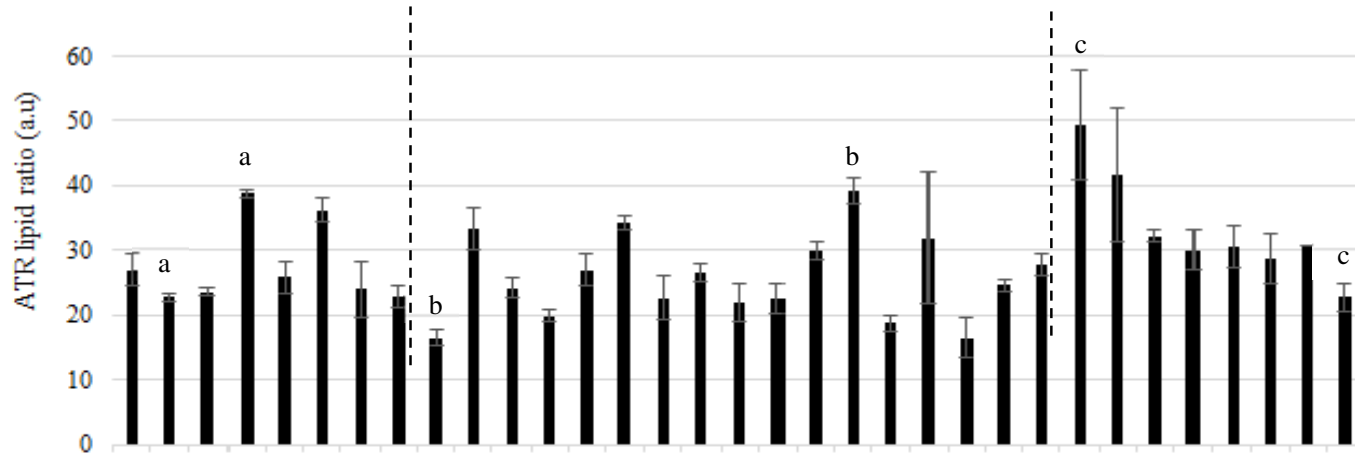

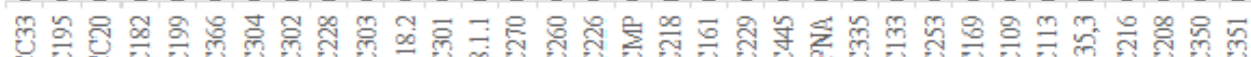

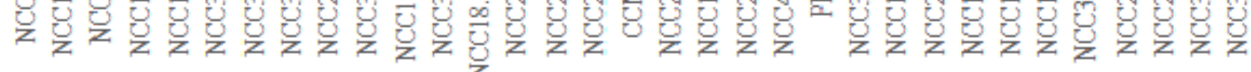


392 Figure 2. Values of the parameters measured for the screened strains includes strain

393 productivity (A), lipid rates as measured with the gravimetric method (B), lipid ratio measured semi-quantitatively by the FTIR approaches, $[(\mathrm{eb}+\mathrm{CH} 3+\mathrm{CH} 3) / \mathrm{si}]$ (C) and [area $\mathrm{eb}+\mathrm{CH} 2+\mathrm{CH} 3$ )/Total area] multiplied by 100 for scaling purposes (D). Notations a, b, and c correspond to the maximum and minimum values for groups 1, 2 and $3 . \mathrm{N}=3$, independent 397 measurements, \pm SD.

\subsection{FTIR analysis}

\subsubsection{FTIR spectrum interpretation}

HTSXT-FTIR analysis was performed on the 33 assayed species (Tab. 3). The lipid

rate was associated to three main signals on the recorded spectra (Fig. 3A), i.e. through the two vibrations of the fatty acid carbon chains $\left(v \mathrm{CH}_{2}\right.$ and $\left.v \mathrm{CH}_{3}\right)\left(v \mathrm{C}-\mathrm{H} \sim 2923\right.$ and $2852 \mathrm{~cm}^{-}$

$\left.{ }^{1}\right)$ [26] and of the ester bond function $(\mathrm{Eb})\left(v \mathrm{C}=\mathrm{O} \sim 1750 \mathrm{~cm}^{-1}\right)$ [63]. The other major bands corresponded to the principal cellular components such as the proteins (the amide I band $v$ $\mathrm{C}=\mathrm{O} \sim 1650 \mathrm{~cm}^{-1}$; the amide II band $\left.\delta \mathrm{N}=\mathrm{H} \sim 1540 \mathrm{~cm}^{-1}\right)$, the nucleic acids $\left(\vee \mathrm{P}=\mathrm{O} \sim 1230 \mathrm{~cm}^{-}\right.$

$\left.{ }^{1}\right)$ and the carbohydrates band superimposed on the silica band $\left(\sim 900-1200 \mathrm{~cm}^{-1}\right)$. For details see Wagner et al., 2010 [64]. Whereas the infrared signature obtained on the whole cells showed superimposed bands of silica and carbohydrates at $1078 \mathrm{~cm}^{-1}$ (Fig. 3A), the signature obtained on the crude lipid extract (Fig. 3B) did not exhibit this band, but a well defined ester bond (Eb) band at $1750 \mathrm{~cm}^{-1}$ and well-defined bands for the $\mathrm{CH}_{2}-\mathrm{CH}_{3}$ signature at $3000-2800$ $411 \mathrm{~cm}^{-1}$.

The lipid ratio estimated from the FTIR data measured on the entire cells (Fig.2C) 413 ranged from $1.70 \pm 0.59$ (Nitzschia sp. 5 NCC109) to $0.49 \pm 0.04$ (Entomoneis paludosa 414 NCC18.1.1). It was thus possible to cluster the assessed strains into three groups. Group 1 415 showed a maximum ratio at $1.69 \pm 0.18$ for Craspedostauros britannicus NCC195 and a 416 minimum at $0.61 \pm 0.01$ for Entomoneis sp 5 NCC302, group 2 showed a maximum ratio at $4171.34 \pm 0.07$ for Fallacia sp 1 NCC303 and a minimum at $0.49 \pm 0.04$ for Entomoneis paludosa 
418 NCC18.1.1 and group 3 showed a maximum ratio at $1.70 \pm 0.59$ for Nitzschia sp NCC109

419 and minimum at $0.56 \pm 0.02$ for Lithodesmium $s p$ NCC35.3.
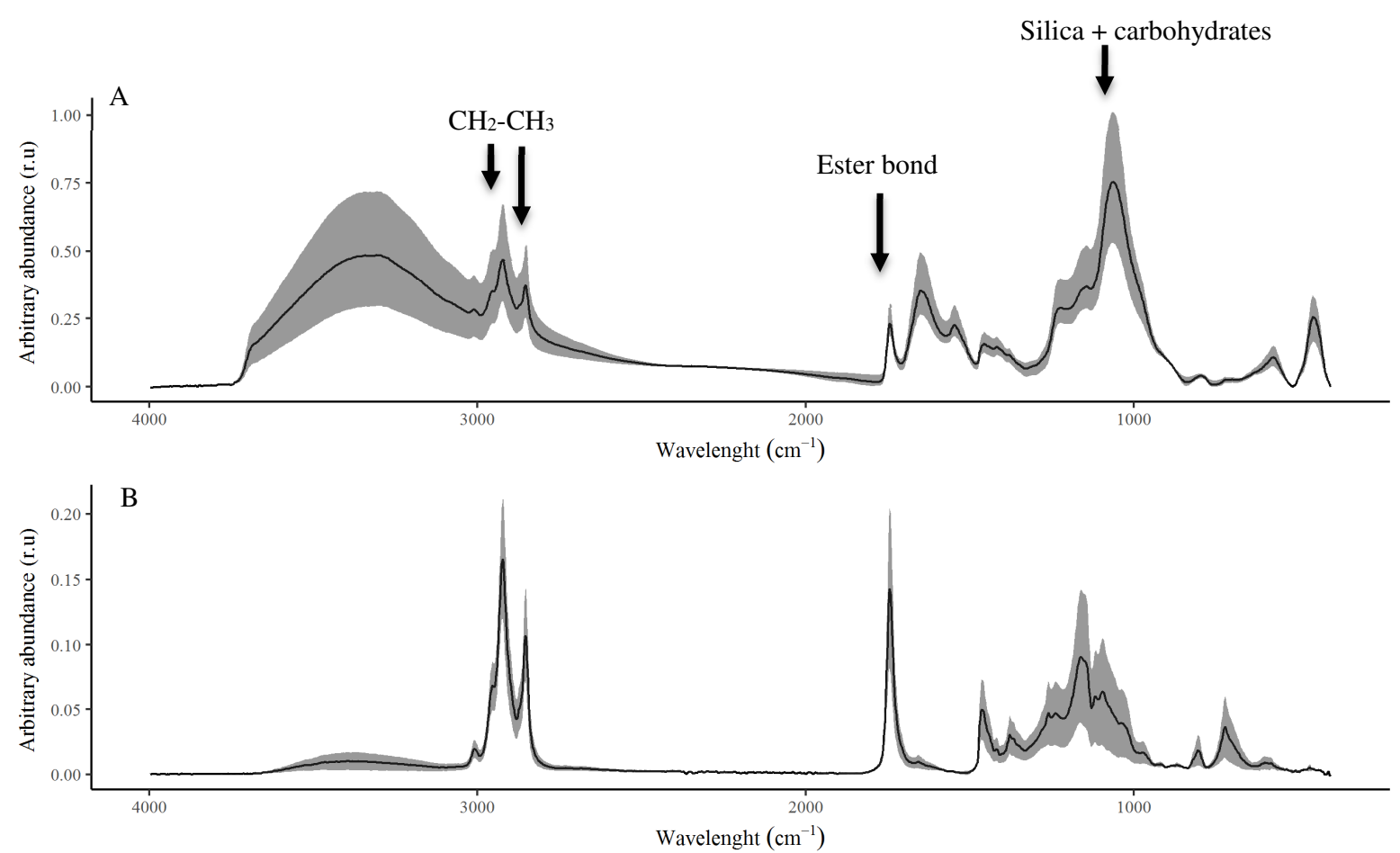

420

421 Figure 3. Example of averaged FTIR spectra recorded on entire cells or on the corresponding lipid extract. (A) Staurosira sp NCC182 FTIR signature recorded on the entire cells and (B) Staurosira sp NCC182 FTIR signature recorded on a crude lipid extract. The grey area corresponds to the variation of the FTIR signal associated to the standard deviation for $n=3$ independent measurements.

The lipid ratio estimated from the FTIR data recorded on the lipid extracts (Fig.2D) ranged from $49.3 \pm 8.5$ (Amphora sp. 2 NCC169) to $16.5 \pm 3.1$ (Entomoneis sp. 6 NCC335). Three groups were also proposed regarding this criterion, group 1 showed a maximum ratio at 38.84 $430 \pm 0.63$ for Staurosira sp. NCC182 and a minimum ratio at $22.8 \pm 1.8$ for Entomoneis sp. 5 431 NCC302, group 2 a maximum ratio at $39 \pm 2$ for Extubocellulus sp. NCC229 and a minimum 432 at $16.5 \pm 1.2$ for Craspedostauros britannicus NCC228 and group 3 with a maximum ratio at 49.3 \pm 8.3 for Amphora sp. 2 NCC169 and a minimum at $23 \pm 2$ for Entomoneis sp. 3 NCC351. 
434 The silica amount did not appear to significantly impact on the lipid FTIR signature except in

435 three species for which the FTIR lipid ratio fell between the two FTIR signature sampling 436 methods (i.e. on entire cells or on lipid extract). These were Craspedostauros brittanicus 437 NCC195, Navicula sp. 4 NCC113 and Conticriba weissflogii CCMP1336. For the other 438 species with different silica content, the lipid signature remained stable in both FTIR sampling 439 methods.

\subsubsection{Multivariate analysis of the FTIR spectra recorded on entire cells}

442 In order to assess the main differences in terms of biochemical composition among the 33 screened strains, a correspondence analysis approach using the lipid, protein and carbohydrate

444 bands normalized to the silica amounts was performed. The resulting map (Fig. 4) is a 445 classification of the data on two main dimensions. Dimension 1 represents $81 \%$ of the initial 446 information and could be associated to the variation of the lipid composition of the assessed 447 strains, ranging from the lowest to the highest amount of total lipids from right to left on the 448 map. Two strains, Staurosira sp. NCC182 and Amphora sp. 2 NCC169 presented the highest 449 amount in total lipids. Along dimension 2, representing 19\% inertia, the strains associated to 450 that dimension were mainly opposed on the basis of their protein and carbohydrate content. 451 Craspedostauros sp. 2 NCC218 was rich in proteins, whereas in Brockmaniella brockmanii 452 NCC161 the main fraction was associated to the carbohydrates.

453 These results indicate that the 2 most notable differences or largest deviations in the sample 454 were observed first between Staurosira sp. NCC182, Amphora sp. 2 NCC169 and the other 455 species for their lipid rates, and secondly between the strains Craspedostauros sp. 2 NCC218, 456 Brockmaniella brockmanii NCC161 and the other species by their respective protein and 457 carbohydrate composition. This analysis summarizes the main biochemical characteristics of 458 the strains hosted in the NCC bank in a single step. Although the distance between the 
macromolecular content and the species were not mathematically defined, their closeness on

460 the map could be used as a guideline to interpret their biochemical characteristics: the squares 461 correspond to the strains particularly rich in lipids, the triangles, the strains rich in 462 carbohydrates and the dots, the strains particularly rich in proteins.

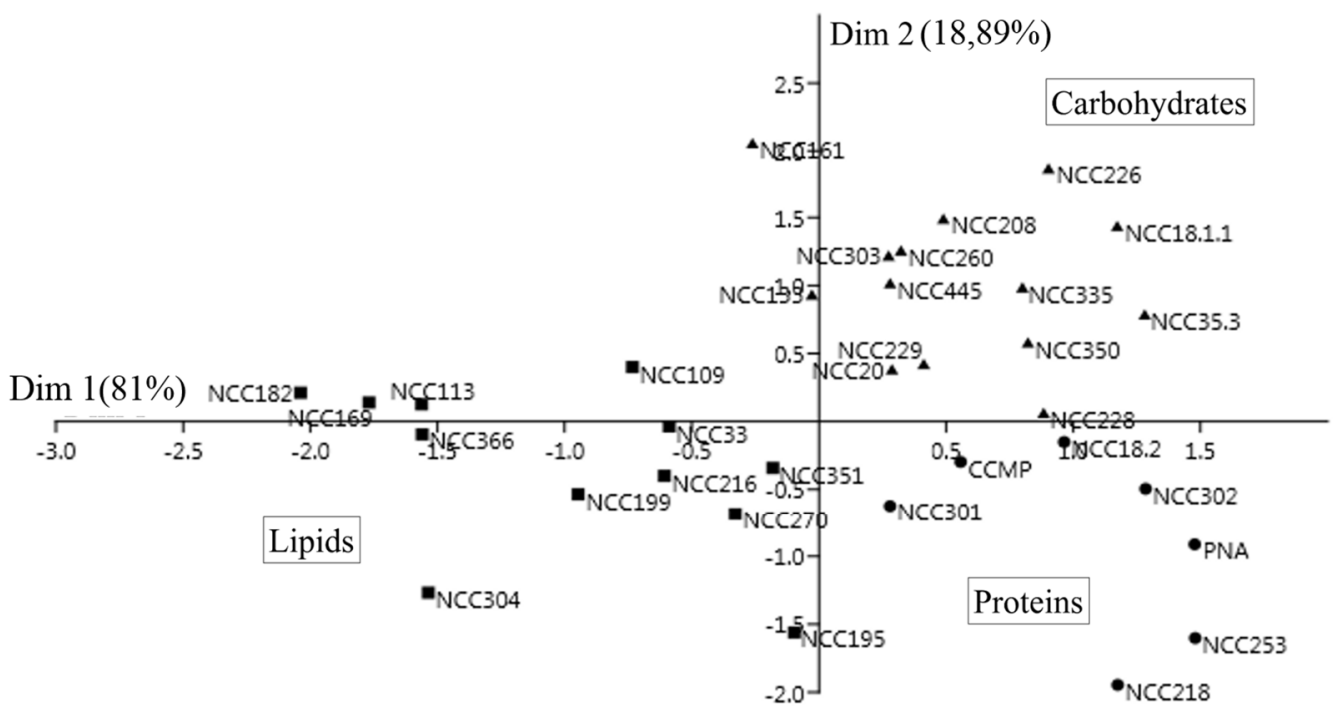

Figure 4. Correspondence analysis map calculated on the basis of the macromolecular content as evaluated by FTIR on all the assayed strains of the NCC. $\mathrm{N}=3$ independent measurements.

3.3 Comparison of the lipid amounts estimated by the gravimetric method and the FTIR approaches.

A significant positive correlation was found for all the techniques (gravimetric and

471 FTIR) $\left(p<1.10^{-7}\right)$ with a Pearson correlation score $\mathrm{R}$ superior to 0.53 . For the 33 analyzed 472 species, 14 presented a high lipid ratio (> 12\% DW) using the gravimetric measurements: 
4741 NCC270, Extubocellulus cf cribriger NCC229, Amphora sp. 1 NCC260, Licmophora sp.1 475 NCC253, Amphora sp. 2 NCC169, Cymatosira belgica NCC208, Amphora acutiuscula 476 NCC216, Navicula sp. 1 NCC113, Craspedostauros britannicus NCC199, Nitzschia sp. 5 477 NCC109 and Entomoneis sp.3 NCC351 (Fig. 2B, Fig. 5). The FTIR method applied on entire 478 cells identified 12 species rich in lipids (FTIR lipid ratio > 1.20) with nine species identified 479 in common with the gravimetric method: NCC33, NCC182, NCC303, NCC270, NCC169, 480 NCC216, NCC113, NCC199 and NCC109 (Fig. 2C, Fig. 5). FTIR for the lipid extract 481 analyses identified 12 species rich in lipids (ATR lipid ratio > 30) with eight species identified 482 in common with the gravimetric approach: NCC182, NCC303, NCC270, NCC229, NCC169, 483 NCC216, NCC113 and NCC109 (Fig 2D, Fig. 5).

484 The correspondence analyses (Fig.4) performed on the FTIR profiles obtained in the entire 485 cells gave supplementary information and identified seven species particularly rich in lipids: 486 NCC182, NCC270, NCC169, NCC113, NCC366, NCC109 and NCC33. These species were 487 also identified by the gravimetric method with the exception of NCC366, only identified by 488 the FTIR method on crude lipid extract. 


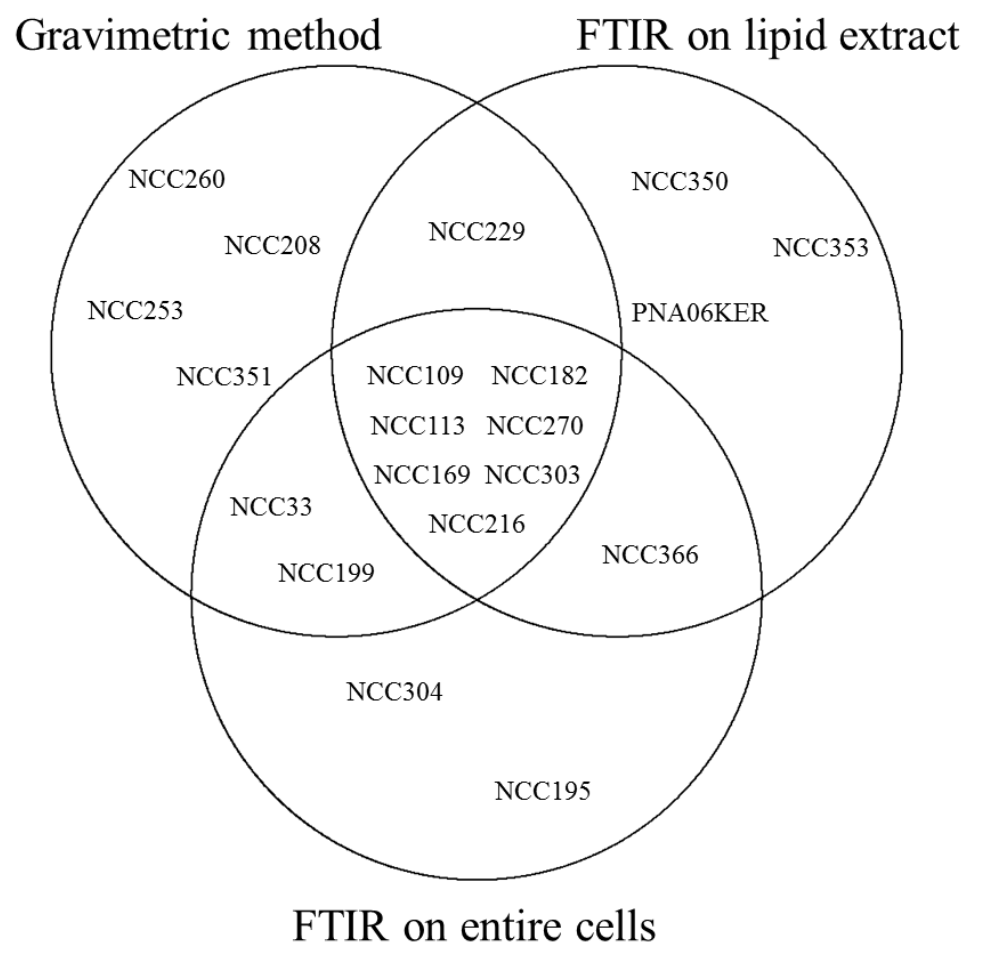

490

Figure 5 Venn diagram showing the degree of overlap among the different approaches 492 used to identify the lipid rich diatoms. In the gravimetric method circle, 14 strains were 493 identified as rich in lipids: 4 only with this method (NCC260, NCC208, NCC253, NCC351), 494 one strains were also identified as rich and lipid by the FTIR on lipid extract (NCC229), and 495 two strains were also identified as rich in lipids by the FTIR on entire cells (NCC33, NCC199). 496 One strain was identified by FTIR on lipid extract and FTIR on whole cells (NCC366) and 497 seven strains were identified as rich in lipids by all three methods (NCC109, NCC182, 498 NCC113, NCC270, NCC169, NCC303, NCC216).

499 
506 The selection of the strains exhibiting both high biomass productivity and high lipid rates, was

507 performed using whole sample distribution based on the lipid rates as estimated by the FTIR 508 approaches, gravimetry and strain biomass productivity as estimated by the fluorometry. On 509 the boxplots summarizing this data (Fig. 6), the colored dots represent the species with the

510 highest potential for biotechnology applications based on lipid molecules: Nitzschia 511 alexandrina NCC33, Staurosira sp NCC182 and Opephora sp NCC366 presented a lipid ratio 512 whatever the considered technique and productivity above the median. Amphora sp 2 NCC169 513 and Nitzschia sp 5 NCC109 were also identified with an above median lipid ratio, but with 514 lower productivity. Both these species were finally selected for their high lipid rate, even 515 though their productivity needs to be improved.

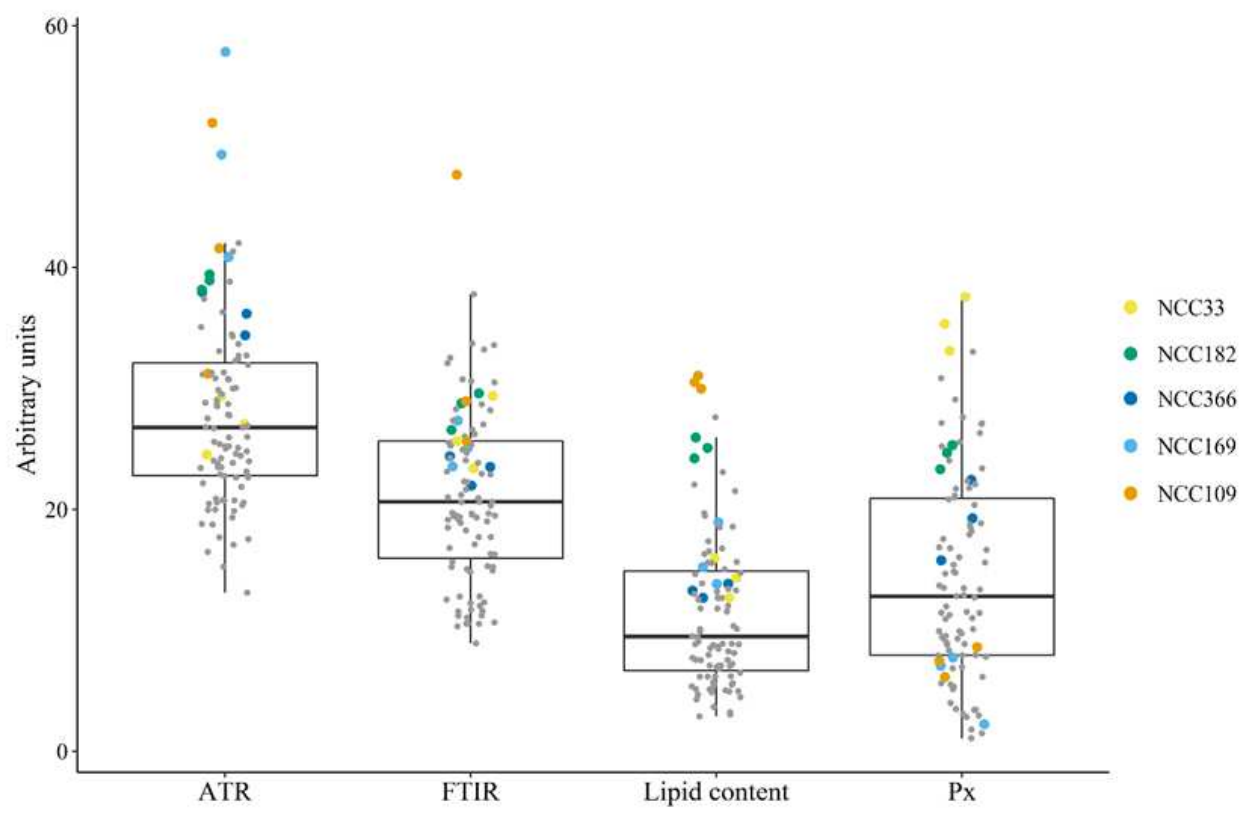

518 Figure 6. Boxplots summarizing the sample distribution criteria as measured with FTIR 519 methods, gravimetry for the lipid rate and flurorimetry for productivity. FTIR data was 520 expressed in arbitrary units. Lipid rate in \%DW and Px in g. $\mathrm{L}^{-1}$.day ${ }^{-1}$ FTIR results were 
multiplied by 20 for scaling purposes. The Px was multiplied by 100 for scaling purposes. 33

522 strains were assayed in independent biological triplicates.

\section{Discussion}

\subsubsection{Determination of growth by fluorimetry}

525

In this study a rapid and precise method for the estimation of cell abundance was needed to efficiently establish the growth parameter of over 60 benthic diatom species. The use of microscope counting chambers is slow, tedious and imprecise. The use of particle counters is feasible only for those phytoplankton species within a certain size range that do not form chains and have long appendages [65]. In vivo fluorescence has been successfully used in the past to monitor the growth of phytoplankton culture [19, 20, 32, 41, 66]. In vivo fluorescence measurement is rapid, sensitive and can be used with all types of diatoms cell structures, i.e. on solitary cells such as Entomoneis and Navicula genera and on chain-forming diatoms, such as Extubocellulus genus or aggregates of cells such as Amphora genus. However, in vivo fluorescence is a measurement of the increase in chlorophyll and chlorophyll per cell varies greatly with light intensity and cellular nutritional status so it can only be used to measure growth when culture conditions are constant. Changes in light and other culture conditions can lead to a change in chlorophyll a content. In this case F0 will also change, introducing a bias in growth rate estimation. Reflectance can also be used to monitor the diatom growth rate, as demonstrated in this study; the NDVI was highly correlated with the cell count as in vivo fluorescence $(\mathrm{R}>0.70)$. Méléder et al, 2003 [21] have already demonstrated this correlation on monospecific benthic diatom cultures with Entomoneis paludosa and Navicula ramosissima. Compared to fluorometry this technique required more culture sampling and a filtration step which took longer to set up. Fluorometry was more sensitive than spectroradiometry and required less material, which made it ideal for very low amounts of 
545 biomass. In vivo fluorometry demonstrated several advantages: ease of use, real-time

546 measurement, non-destructive sampling.

548 The total lipid evaluation by gravimetry has been used for more than 50 years [67], but this

549 technique is clearly not compatible with screening efforts involving large numbers of samples

550 because of processing time required particularly in the extraction phase. Furthermore, large

551 volumes of samples are systematically needed for the measurements. It also requires sufficient

552 amounts of dried biological sample, thus making it unsuitable for high frequency monitoring

553 of small scale microalgal cultivation. Feng et al., (2013) [68] suggested that the presence of

554 chlorophyll could also affect the accuracy of the method. In comparison to conventional

555 chemical analysis, FTIR spectroscopy presented striking advantages due to its high reliability,

556 sensitivity and speed of the measurement [64]. An IR spectrometer coupled to a microtiter 557 plate reader open the possibility of high throughput analysis of a few nanograms of cell 558 material [69]. Coat et al, (2014) [26] demonstrated that the repeatability of FTIR signal 559 reached excellent values (10\%), but only for a limited range of analyzed quantities of matter $560 \quad\left(10^{6}\right.$ to $10^{8}$ cells. $\left.\mathrm{mL}^{-1}\right)$.

561 In the present study we have demonstrated that FTIR was a suitable technique to evaluate the

562 lipid ratio of diatoms. The use of the FTIR technique was even more rapid, due to the use of 563 direct fresh biomass. The results obtained on entire cells and lipid crude extracts were similar, 564 suggesting that measurement on entire cells did not improve the lipid quantification. 565 Measurement on whole cells could be considered sufficient to get a first idea on their 566 intracellular lipid rate. In addition, removing the silica did not seem necessary in view of the 567 present results to improve the lipid semi-quantification.

568 However, there are some limitations with this non-invasive technique. Even though the FTIR 569 results between entire cells and crude extracts were similar, we did not obtain a perfect linear 
correlation with the traditional lipid extraction. Nevertheless, the FTIR method has the

571 advantage of simultaneously detecting the relative amount of lipids, carbohydrates and

572 proteins, even though those components overlapped, implying a certain degree of inaccuracy.

573 The different steps required for the lipid extraction can also produce a bias in the evaluation

574 of the lipid quantity, added to the inaccuracy of weighing of the lipid matter, making it less

575 precise than the spectrometric approach. The heterogeneity observed in the present FTIR

576 results could be also associated to the utilization of different strains (33 strains in the current

577 study). These are not described in the previous studies evaluating lipid quantification with

578 FTIR where only one species was used [26, 39, 70]. FTIR did not differentiate polar/apolar

579 lipids, or the different types of fatty acids produced by the strains. Lipid analysis by

580 chromatographic techniques coupled to mass spectrometry will be needed to further identify

581 the presence of interesting molecules like EPA or DHA. Nevertheless, the present study opens

582 the way to rapid and reliable semi-quantification of total amounts of intracellular lipids in

583 diatoms using a fast, non-invasive approach.

584

585

586

587

588

589

590

591

592

593 
595 This study highlighted the efficiency of PAM and FTIR measurements as fast techniques to 596 characterize both the growth and lipid content of microalgae (Tab.4). The use of PAM 597 fluorometry was three times faster than cell counting. Where 15 minutes were necessary to 598 count 3 samples (8.25 hours for 99 samples) and 10 minutes to measure reflectance by spectroradiometry (5.5 hours for 99 samples), only 5 minutes were necessary to measure F0 by PAM fluorometry (2.75 hours for 99 samples).

601 Table 4 Evaluation of three methods for algal growth kinetic determination

\begin{tabular}{llll}
\hline Evaluation index & Counting & NDVI & PAM \\
\hline Cultivation scale & Large & Large-small & Large-small \\
Monitoring frequency & High & Medium & High \\
Sample state & Liquid & Filtered & Liquid \\
Volume consumed & $5-1 \mathrm{~mL}$ & $5-3 \mathrm{~mL}$ & $>1 \mathrm{~mL}$ \\
Time consumed & $8.25 \mathrm{~h}$ & $5.5 \mathrm{~h}$ & $2.75 \mathrm{~h}$ \\
Equipment & Counting chambers & Spectroradiometer & PAM fluorometer \\
Reliability & Low & High & High \\
\hline
\end{tabular}

602

603 For lipid extraction, dichloromethane methanol solvent is usually used [34, 71-73]. Even

604 though extraction was very effective, this method is known to have environmental and health 605 risks [71]. Moreover, it is expensive: for 99 extractions, $10 \mathrm{~L}$ of each solvent was necessary 606 costing $234 €(9.68 € / \mathrm{L}$ of methanol and $13.72 € / \mathrm{L}$ of dichloromethane (Fischer Scientific).

607 The time necessary for the lipid extraction using Bligh and Dyer method was time-consuming 608 (Tab. 5) due to the time needed for maceration and lipid separation. 5.5 weeks were necessary 609 to perform the extraction of 99 samples (ca. 7920 hours). Nile red, a lipid soluble fluorescent 610 dye, is commonly used to evaluate the lipid content of animal cells, microorganisms, and 611 especially microalgal strains. Required time to perform spectrophotometric measurements 612 with Nile red and Bodipy was evaluated at 10 mins per sample (measurement before and after 613 Nile red or Bodipy application) and 25 to 40 mins incubation time was necessary after 
614 application of Nile red or Bodipy before reading spectrophotometric values $[68,74]$. In

615 comparison FTIR is a fast and eco-friendly technique. Two plates of 384 well were necessary 616 to evaluate the lipid content for the 33 strains (each strain needed 15 wells with 5 wells per

617 replicate). It took 30 seconds to read each well to obtain the FTIR spectra leading to ca. and 4

618 hours to read an entire plate.

619 Table 5 Evaluation of three methods for algal lipid content determination

\begin{tabular}{llll}
\hline Evaluation index & Gravimetric & FT-IR & Nile Red / Bodipy 505/515 \\
\hline Cultivation scale & Large & Large-small & Large-small \\
Monitoring frequency & Low & Medium & High \\
Sample state & Dried & Liquid & Liquid \\
Biomass consumed & $100 \mathrm{mg}$ & $5 \mu \mathrm{L}$ of $1.0 \mathrm{mg} \mathrm{mL}^{-1}$ & $3 \mathrm{~mL}$ of $\mathrm{OD}_{680} 0.4$ \\
Time consumed & $>50 \mathrm{~h}$ & $8 \mathrm{~h}$ & $25 \mathrm{~h}$ \\
Equipment & Nitrogen evaporator & FT-IR & FS \& FM a \\
Accuracy & Total lipid & Total lipid & Neutral lipid \\
\hline
\end{tabular}

$620 \quad{ }^{a}$ Fluorescence spectrophotometer and Fluorescence microscopy

621 Nile red and Bodipy 505/515 staining are powerful quantification tools in terms of time and 622 cost of biomass $[75,76]$, high throughput quantification method of lipids with Nile red or 623 Bodipy 505/515 fluorescence can hardly been seen as a method for screening different species 624 of microalgae, as the staining protocol is species specific. The significant disadvantages of 625 Nile red were its limited photostability, interference with chlorophyll [77, 78], and difficulty 626 of permeation for some species. Bodipy 505/515 produced a better marker than Nile red for 627 visualizing neutral lipid content in fluorescence microscopy [75, 79] but some authors have reported disadvantages with these techniques such as background fluorescence of the dye in

629 the medium and failure to quantify neutral lipids between rich and low oil strains. When 630 microalgae were cultured on a large scale with a low-frequency monitoring requirement, any 631 of the three methods could be adopted, although gravimetric determination might be 632 preferable as it was an absolute method for quantification of both crude and neutral lipids 633 without the need of specialized equipment. For the general laboratory culture of microalgae, 
634 the FT-IR method for simultaneous characterization of total lipid, carbohydrate and protein

635 content and the Nile Red method for both neutral lipid content and location can be used, both

636 of which are relative quantification methods, but require special equipment.

637 Although these analyses demonstrate that FTIR and Nile Red were equally effective at 638 measuring lipid accumulation, FTIR was likely to be a more efficient tool for this purpose 639 because of its much faster analysis time and high reproducibility of results [80]. Furthermore,

640 FTIR may also be more suitable than Nile Red for efficiently detecting large increases in lipid 641 concentration. Nile Red does not appear to be efficient at accurately quantifying lipid 642 concentration above $20 \mathrm{mg} / \mathrm{ml}$ [77] while FTIR can efficiently detect linear lipid 643 concentration changes up to at least $250 \mathrm{mg}$ [81]. Measurements with FTIR were more precise 644 because of the technical quintuplicate performed for the acquisition of spectra.

\subsection{Screening for lipid rich benthic diatom strains}

646 The aim of this study was to investigate the growth characteristics and the lipid rates of the 647 benthic marine diatom species hosted in the NCC bank in order to evaluate their potential for 648 original lipid bioproducts of potential economic interests. First, a selection based on the genera 649 identified in the literature was applied. Among the 134 strains hosted by the NCC, 650 corresponding to 40 genera and 101 species, 23 genera (corresponding to 77 species, 105 strains in the NCC) were largely studied $[15,16,42,43,46,49,52,55,58,60,82]$. Among

652 these 23 genera, only 13 genera (42 species, 47 strains) with high productivity and/or 653 producing high lipid quantities were selected for the current study. Among these 47 strains, 654 only 18 strains, (6 genera, 17 species) grew successfully. Among the NCC's 40 genera, 17 genera (corresponding to 24 species, 29 strains) were not previously reported in the literature in terms of productivity or ability to produce lipids or added value molecules. Thus, the 29

657 strains corresponding to these 17 genera were also selected and assayed for the current study. 658 Among these strains, 15 strains (13 species, 10 genera) did successfully grow. Finally, at the 
659 end of this first screening step based on the growth rates, 33 strains (18 previously described

660 and 15 that have never been described before in the literature) were selected for the second step of the screening process. As reported in the supplementary data, 43 strains failed to grow which may be associated to shear stress; some species like Rhizosolenia setigera cells were 663 broken during agitation.

664 The second step consisted in the determination of the lipid rate on the selected strains. In 665 microalgae, it can typically vary from 1 to $85 \%$ of the dry weight under adverse conditions $666[15,83,84]$. Factors such as temperature, irradiance and most markedly nutrient availability 667 have been shown to affect both lipid composition and lipid rate $[17,57,85]$. In general, high 668 irradiance stimulates TAG accumulation [57], while under low irradiance, the polar lipids 669 (phospholipids and glycolipids), structurally and functionally associated to cell membrane, 670 are preferentially synthesized [17]. The lipid rate found in the current study for the Amphora 671 genus was similar to that estimated by Renaud et al., (1999) [46]. The authors proposed 19\% 672 DW vs. 14 to $19 \%$ DW in the current study. This similarity could be explained by the similar 673 culture conditions for light and nutrient although the temperature was different $\left(25^{\circ} \mathrm{C} v s 16^{\circ} \mathrm{C}\right.$ 674 in the current study). According to Chtourou et al., 2015 [61], the temperature could be an 675 important factor for Amphora genus lipid rate which can achieve lipid rates up to $24 \%$ of DW 676 at $20^{\circ} \mathrm{C}$. Media enrichment could also be an important factor: Amphora cells grown in media 677 enriched with macronutrients and trace metal can also achieve lipid rates up to $32 \%$ under low 678 light conditions $\left(11.4 \mu \mathrm{mol}\right.$ photon $\left.\mathrm{m}^{-2} \mathrm{~s}^{-1}\right)$ [62] or under nitrogen deficiency [55]. These 679 factors could be used as guideline to improve lipid production of the selected Amphora strains 680 hosted in the NCC. The biomass measurements for the Amphora genus in Zhao et al study 681 [49] were in accordance with our results. The authors found 0.13 g.L. $\mathrm{L}^{-1}$ vs. 0.16 g.L $\mathrm{L}^{-1}$ in the 682 current study. According to their measured lipid productivity, the Amphora genus appeared 683 to be a good candidate for lipid based potential applications. 
684 The lipid rate found in our study for the Nitzschia genus was similar to the results found by 685 Renaud et al., (1999) for one species [46] but very different for Nitzschia sp 5 NCC109 in the current study. They found a lipid rate of between 13 and 16\% DW for the Nitzschia genus. In the present study, Nitzschia alexandrina NCC33 showed a lipid rate of $13 \%$ DW but for Nitzschia sp 5 NCC109 it was estimated up to 30\% DW. However, this rate could only be found for Nitzschia genus under nitrogen or silica deficiency increasing up to 45-47\% DW $690[44,45,47]$. Since the amount of nitrogen was not monitored in the culture, it is possible that nitrogen depletion occurred, explaining the high lipid rate measured for Nitzschia sp 5 NCC109. Further analysis for this strain is necessary to establish whether this was due to the absolute lipid richness of the strain, or to a bias in culture conditions. The biomass found for the Nitzschia genus in Zhao et al (2016) [49] was lower than the measurements in the present study. The biomass estimated in the current study ranged from 0.07 to 0.14 g.L. $\mathrm{L}^{-1}$ vs. 0.19 to 0.23 g.L $\mathrm{L}^{-1}$. This difference could be due to the light/dark cycle culture conditions, suggesting that under continuous light the biomass production would be more significant for this specific genus [86].

699 It has been demonstrated that the species with a lipid rate of $30 \%$ DW and productivity under 700 non-optimized conditions of around $0.30 \mathrm{~g} . \mathrm{L}^{-1}$ could be potential strains for lipid production $701[15,87]$. In the present study Nitzschia sp 5 NCC109 had the highest lipid rate, 30.51\% DW, 702 Nitzschia alexandrina NCC33 with the highest productivity 0.35 g. $\mathrm{L}^{-1}$. Both strains were thus selected as candidates for further analyses to assay their potential for lipid-based applications. The Navicula genus also presented a lipid rate for the 2 tested species of between $9 \%$ and $23 \%$ DW. Zhao et al, (2016) [49] found a lipid range from 5 to $30 \%$ for 3 Navicula species (Navicula ramosissima, Navicula molli and Navicula halophia) and Scholz et al, (2013) [58] between 18-25\% for 6 Navicula species (Navicula digito-radiata, Navicula forcipata, 
data were estimated in spite of very different culture conditions (dark night cycle at $600 \mu \mathrm{mol}$

710 photon $\mathrm{m}^{-2} \mathrm{~s}^{-1}$ ). This observation is important, since for that specific genus, the observed

711 variability in the range of lipid rate for the different tested species is the same regardless of

712 the culture conditions used. The biomass measurements found by Zhao et al., (2016) for the

713 Navicula genus are in accordance with the present study, ranging from 0.10 to $0.17 \mathrm{~g} . \mathrm{L}^{-1}$ vs.

7140.13 to 0.17 g. $\mathrm{L}^{-1}$ suggesting that this genus could produce the identical biomass quantity

715 under light/dark cycle or continuous light.

716 The lipid rate found for the Extubocellulus genus in Slocombe et al., (2015) [60] was 23\%

717 DW and the biomass equalled $0.06 \mathrm{~g} . \mathrm{L}^{-1}$. The lipid rate for this genus, $15 \% \mathrm{DW}$ in the actual

718 study was lower but the biomass obtained was higher $0.16 \mathrm{~g} . \mathrm{L}^{-1}$. The culture was grown under

719 light/dark cycle in the Slocombe et al. study suggesting that this genus could grow better under

720 continuous light but produce more lipids under light/dark cycle. Wahidin et al., (2013) [88]

721 found the same trend for the microalgae genus Nannochloropsis.

722 Knuckey et al, (2002) [52] found 27\% DW of lipid rate for the Entomoneis genera. In the 723 present study 9 strains of Entomoneis presented lipid rates ranging from 3 to $13 \%$ DW. In the

724 Knuckey et al, (2002) study the $\mathrm{pH}$ and the nutrients were monitored. The culture conditions

725 were identical to the present study (continuous light, $120 \mu \mathrm{mol}$ photon $\mathrm{m}^{-2} \mathrm{~s}^{-1}$ ). It is therefore 726 possible, that for this genus a nutrient limitation occurred and instead of enhancing the lipid

727 production, it has diminished it. It has been reported that this species produces EPA which is 728 interesting for nutraceutical products [52].

729 In this study the species with the highest lipid rate $(\sim 20 \%)$ and the greatest biomass 730 productivity (up to 0.24 g.L $\mathrm{L}^{-1}$.day ${ }^{-1}$ ) was Staurosira sp NCC182. This species was similar in 731 productivity to the marine microalgae Nannochloropsis sp. with productivity higher than 0.21

732 g. $\mathrm{L}^{-1}$.day ${ }^{-1}$ and reached a total lipid rate of $30 \% \mathrm{DW}$, when cultivated in batch mode under 733 continuous light and reached 68\% DW of lipid production under nitrogen deprivation [89]. 
734 Nannochloropsis sp. was investigated for algal biofuel production due to its ease of growth

735 and high oil rate. Staurosira sp was grown in raceway ponds by Huntley et al., (2015) [16]

736 and the lipid quantification demonstrated that these strains could reach a lipid rate of $45.5 \%$

737 DW under low N content. In the present study, Staurosira sp. NCC182 presented all the 738 characteristics (good productivity and oil content) to be produced on a large scale and was 739 considered to be one of the most promising candidates for lipid-based applications.

740 Even if the microalgae oil yield is strain-dependent it is generally superior to other vegetable crops $[15,87]$. Oil content in Corn, Hemp, Soybean, Sunflower or Palm oil varied from 18 (Soybean) to 44\% DW (Corn). Christie et al., (2007) [15] demonstrated that microalgae with a lipid rate up to $30 \%$ of DW could produce $58 \mathrm{~L} / \mathrm{Ha}$ of oil and microalgae up to $70 \%$ of DW could produce $136 \mathrm{~L} / \mathrm{Ha}$ of oil. Corn can produce $172 \mathrm{~L} / \mathrm{Ha}$, soybean $446 \mathrm{~L} / \mathrm{Ha}$ and oil palm $5950 \mathrm{~L} / \mathrm{Ha}$ but require a lot of land for production: $1540 \mathrm{M} / \mathrm{Ha}$ for Corn, $594 \mathrm{M} / \mathrm{Ha}$ for Soybean and $45 \mathrm{M} / \mathrm{Ha}$ for oil palm. Microalgae production only requires 2 to $5 \mathrm{M} / \mathrm{Ha}$. In the NCC collection Nitzschia sp 5 NCC109 and Staurosira sp NCC182 had all the mandatory features to be grown on a large scale: good productivity and high lipid rate. In the present study, Nitzschia alexandrina NCC33 had the highest productivity in the NCC collection $(0.36$ g. $\mathrm{L}^{-1} \cdot$ day $^{-1}$ ) and presented a lipid rate superior to $10 \%$ DW. Despite its low productivity of 0.08 g.L.-1.day ${ }^{-1}$, Amphora sp 2 NCC169 was chosen for its lipid rate, superior to $15 \%$ DW. These 4 strains were selected for further analyses and to improve their productivity and lipid rate with the objective of supplying new resources for lipid based applications. Entomoneis

754 paludosa was also selected despite its low lipid rate since it was already characterized for its 755 ability to produce EPA.

756 Among the strains not described in the literature, the measured lipid rate ranged from 3 to $20 \%$ DW and productivity from 0.05 to 0.27 g.L $\mathrm{L}^{-1}$.day ${ }^{-1}$. Only one genus was selected for further study: Opephora sp 1 NCC366. This species showed a mandatory balance between 

DW).

\section{Conclusion ssep}

In this work, we focused on developing an easy to use screening method to explore the

763

764

NCC bank for diatom strains with the highest relative lipid content. The experimental results showed that the combined use of water-PAM to estimate strain growth kinetics and FTIR on whole cells to estimate the semi-quantitative strain macromolecular content and more specifically lipids, could be rapid, reliable and accessible techniques. The developed methodology opens the way to a systematic, fast, and convenient screening of microorganisms (microalgae in this proof of concept). Moreover, the sensitivity and specificity of the method makes it suitable for a reasonable amount of biomass. This method could also be used in systematic studies for the optimization of culture conditions and to measure the influence of the environment on the metabolic plasticity of the assessed organism. Using this screening approach, 5 strains hosted in the NCC bank were selected for their high productivity and high lipid rate: Nitzschia alexandrina NCC33, Staurosira sp NCC182, Opephora sp 1 NCC366, Nitzschia sp 5 NCC109 and Amphora sp 2 NCC169. The lipid rate achieved by theses strains reached a maximum of $30 \% \mathrm{DW}$ in the assayed cultivation conditions.

In order to improve the lipid quantity, the selected strains could be grown under different culture conditions. The impact of light, temperature and nutrients, especially nitrogen, could be assayed both in terms of lipid productivity and ecophysiology to ensure the highest growth rate possible. Once optimal conditions are found for those strains, the production in photobioreactors could be tested and productivity and lipid rates evaluated, in order to 
782 estimate quantitatively if the selected strains can compete with the best ones found in the

783 literature [90-92]. Finally, depending on their oil quality and original lipid activities, those

784 strains may constitute new and original genetic resources that could have potential interesting

785 applications (biodiesel, pharmaceutical, etc.).

786

787

788

789

790

791

792

793

794

795

796

797

798

799

800

801

802

\section{References}

803 [1] T.M. Mata, A.A. Martins, N.S. Caetano, Microalgae for biodiesel production and other

804

805

806

807 applications: A review, Renew. Sustain. Energy Rev. 14 (2010) 217-232. doi:10.1016/j.rser.2009.07.020.

[2] P. Spolaore, C. Joannis-Cassan, E. Duran, A. Isambert, Commercial applications of microalgae, J. Biosci. Bioeng. 101 (2006) 87-96. doi:10.1263/jbb.101.87. 
[3] M.A. Borowitzka, High-value products from microalgae-their development and commercialisation, J. Appl. Phycol. 25 (2013) 743-756. doi:10.1007/s10811-013-99839.

[4] M.I. Khan, J.H. Shin, J.D. Kim, The promising future of microalgae: current status, challenges, and optimization of a sustainable and renewable industry for biofuels, feed, and other products, Microb. Cell Factories. 17 (2018). doi:10.1186/s12934-018-0879-x.

[5] Y.-F. Niu, M.-H. Zhang, D.-W. Li, W.-D. Yang, J.-S. Liu, W.-B. Bai, H.-Y. Li, Improvement of Neutral Lipid and Polyunsaturated Fatty Acid Biosynthesis by Overexpressing a Type 2 Diacylglycerol Acyltransferase in Marine Diatom Phaeodactylum tricornutum, Mar. Drugs. 11 (2013) 4558-4569. doi:10.3390/md11114558.

[6] Z. Yi, M. Xu, X. Di, S. Brynjolfsson, W. Fu, Exploring Valuable Lipids in Diatoms, Front. Mar. Sci. 4 (2017). doi:10.3389/fmars.2017.00017.

[7] E. Artamonova, J. Svenning, T. Vasskog, E. Hansen, H. Eilertsen, Analysis of phospholipids and neutral lipids in three common northern cold water diatoms: Coscinodiscus concinnus, Porosira glacialis, and Chaetoceros socialis, by ultra-high performance liquid chromatography-mass spectrometry, J. Appl. Phycol. 29 (2017) 1241-1249.

[8] K.W. Chew, J.Y. Yap, P.L. Show, N.H. Suan, J.C. Juan, T.C. Ling, D.-J. Lee, J.-S. Chang, Microalgae biorefinery: High value products perspectives, Bioresour. Technol. 229 (2017) 53-62. doi:10.1016/j.biortech.2017.01.006.

[9] G.A. Dunstan, J.K. Volkman, S.M. Barrett, J.-M. Leroi, S.W. Jeffrey, Essential polyunsaturated fatty acids from 14 species of diatom (Bacillariophyceae), Phytochemistry. 35 (1993) 155-161. doi:10.1016/S0031-9422(00)90525-9.

[10] Y.-C. Chen, The biomass and total lipid content and composition of twelve species of marine diatoms cultured under various environments, Food Chem. 131 (2012) 211-219. doi:10.1016/j.foodchem.2011.08.062.

[11] L. Chuecas, J.P. Riley, Component Fatty Acids of the Total Lipids of Some Marine Phytoplankton, J. Mar. Biol. Assoc. U. K. 49 (1969) 97. doi:10.1017/S0025315400046439.

[12] K. Nagao, T. Yanagita, Conjugated fatty acids in food and their health benefits, J. Biosci. Bioeng. 100 (2005) 152-157. doi:10.1263/jbb.100.152.

[13] M. Gross, The mysteries of the diatoms, Curr. Biol. 22 (2012) R581-R585. http://www.sciencedirect.com/science/article/pii/S0960982212008664 (accessed September 12, 2016).

[14] T. Lebeau, J.-M. Robert, Diatom cultivation and biotechnologically relevant products. Part II: Current and putative products, Appl. Microbiol. Biotechnol. 60 (2003) 624-632. doi:10.1007/s00253-002-1177-3.

[15] Y. Chisti, Biodiesel from microalgae, Biotechnol. Adv. 25 (2007) 294-306. doi:10.1016/j.biotechadv.2007.02.001.

[16] M.E. Huntley, Z.I. Johnson, S.L. Brown, D.L. Sills, L. Gerber, I. Archibald, S.C. Machesky, J. Granados, C. Beal, C.H. Greene, Demonstrated large-scale production of marine microalgae for fuels and feed, Algal Res. 10 (2015) 249-265. doi:10.1016/j.algal.2015.04.016.

[17] Q. Hu, M. Sommerfeld, E. Jarvis, M. Ghirardi, M. Posewitz, M. Seibert, A. Darzins, Microalgal triacylglycerols as feedstocks for biofuel production: perspectives and advances, Plant J. 54 (2008) 621-639. doi:10.1111/j.1365-313X.2008.03492.x.

[18] T.A. Dempster, M.R. Sommerfeld, Effects of environmental conditions on growth and lipid accumulation in Nitzschia communis (Bacillariophyceae), J. Phycol. 34 (1998) $712-721$. 
[19] V. Vyhnalek, Z. Fišar, A. Fišarová, J. Komarkova, In vivo fluorescence of chlorophyll a: Estimation of phytoplankton biomass and activity in Rímov Reservoir (Czech Republic), Water Sci. Technol. 28 (1993) 29-33. http://wst.iwaponline.com/content/28/6/29.abstract (accessed October 10, 2017).

[20] A.D. Steinman, G.A. Lamberti, P.R. Leavitt, D.G. Uzarski, Biomass and Pigments of Benthic Algae, in: Methods Stream Ecol. Vol. 1, Elsevier, 2017: pp. 223-241. doi:10.1016/B978-0-12-416558-8.00012-3.

[21] V. Méléder, L. Barillé, P. Launeau, V. Carrère, Y. Rincé, Spectrometric constraint in analysis of benthic diatom biomass using monospecific cultures, Remote Sens. Environ. 88 (2003) 386-400. doi:10.1016/j.rse.2003.08.009.

[22] L. Akoto, R. Pel, H. Irth, A.T. Udo, R.J. Vreuls, Automated GC-MS analysis of raw biological samples: Application to fatty acid profiling of aquatic micro-organisms, $\mathrm{J}$. Anal. Appl. Pyrolysis. 73 (2005) 69-75.

[23] K.E. Cooksey, J.B. Guckert, S.A. Williams, P.R. Callis, Fluorometric determination of the neutral lipid content of microalgal cells using Nile Red, J. Microbiol. Methods. 6 (1987) 333-345.

[24] J. Koreivienè, Microalgae Lipid Staining with Fluorescent BODIPY Dye, (2017).

[25] D. Jaeger, C. Pilger, H. Hachmeister, E. Oberländer, R. Wördenweber, J. Wichmann, J.H. Mussgnug, T. Huser, O. Kruse, Label-free in vivo analysis of intracellular lipid droplets in the oleaginous microalga Monoraphidium neglectum by coherent Raman scattering microscopy, Sci. Rep. 6 (2016) 35340.

[26] R. Coat, V. Montalescot, E.S. León, D. Kucma, C. Perrier, S. Jubeau, G. Thouand, J. Legrand, J. Pruvost, O. Gonçalves, Unravelling the matrix effect of fresh sampled cells for in vivo unbiased FTIR determination of the absolute concentration of total lipid content of microalgae, Bioprocess Biosyst. Eng. 37 (2014) 2175-2187.

[27] J. Fan, Y. Cui, M. Wan, W. Wang, Y. Li, Lipid accumulation and biosynthesis genes response of the oleaginous Chlorella pyrenoidosa under three nutrition stressors, Biotechnol. Biofuels. 7 (2014) 17. doi:10.1186/1754-6834-7-17.

[28] P. Metzger, C. Largeau, Botryococcus braunii: a rich source for hydrocarbons and related ether lipids, Appl. Microbiol. Biotechnol. 66 (2005) 486-496. doi:10.1007/s00253-0041779-z.

[29] R.R. Guillard, Culture of phytoplankton for feeding marine invertebrates, in: Cult. Mar. Invertebr. Anim., Springer, 1975: pp. 29-60.

[30] R.R. Guillard, J.H. Ryther, Studies of marine planktonic diatoms: I. Cyclotella Nana Hustedt, and Detonula Confervacea (CLEVE) Gran., Can. J. Microbiol. 8 (1962) 229239.

[31] Z.-K. Yang, Y.-F. Niu, Y.-H. Ma, J. Xue, M.-H. Zhang, W.-D. Yang, J.-S. Liu, S.-H. Lu, Y. Guan, H.-Y. Li, Molecular and cellular mechanisms of neutral lipid accumulation in diatom following nitrogen deprivation, Biotechnol. Biofuels. 6 (2013) 67. https://biotechnologyforbiofuels.biomedcentral.com/articles/10.1186/1754-6834-6-67 (accessed October 6, 2017).

[32] C. Honeywill, D. Paterson, S. Hagerthey, Determination of microphytobenthic biomass using pulse-amplitude modulated minimum fluorescence, Eur. J. Phycol. 37 (2002) 485492. doi:10.1017/S0967026202003888.

[33] B. Gompertz, XXIV. On the nature of the function expressive of the law of human mortality, and on a new mode of determining the value of life contingencies. In a letter to Francis Baily, Esq. FRS \&c, Philos. Trans. R. Soc. Lond. 115 (1825) 513-583.

[34] E.G. Bligh, W.J. Dyer, A RAPID METHOD OF TOTAL LIPID EXTRACTION AND PURIFICATION, Can. J. Biochem. Physiol. 37 (1959) 911-917. doi:10.1139/y59-099. 
[35] G. Breuer, W.A. Evers, J.H. de Vree, D.M. Kleinegris, D.E. Martens, R.H. Wijffels, P.P. Lamers, Analysis of fatty acid content and composition in microalgae, J. Vis. Exp. JoVE. (2013).

[36] E.S. León, R. Coat, B. Moutel, J. Pruvost, J. Legrand, O. Gonçalves, Influence of physical and chemical properties of HTSXT-FTIR samples on the quality of prediction models developed to determine absolute concentrations of total proteins, carbohydrates and triglycerides: a preliminary study on the determination of their absolute concentrations in fresh microalgal biomass, Bioprocess Biosyst. Eng. 37 (2014) 23712380.

[37] W. Zeroual, C. Choisy, S.M. Doglia, H. Bobichon, J.-F. Angiboust, M. Manfait, Monitoring of bacterial growth and structural analysis as probed by FT-IR spectroscopy, Biochim. Biophys. Acta BBA - Mol. Cell Res. 1222 (1994) 171-178. doi:10.1016/01674889(94)90166-X.

[38] D.H. Williams, I. Fleming, Spectroscopic methods in organic chemistry, McGraw-Hill, 1980.

[39] I. Schaub, H. Wagner, M. Graeve, U. Karsten, Effects of prolonged darkness and temperature on the lipid metabolism in the benthic diatom Navicula perminuta from the Arctic Adventfjorden, Svalbard, Polar Biol. (2017) 1-15. doi:10.1007/s00300-0162067-y.

[40] N. Sourial, C. Wolfson, B. Zhu, J. Quail, J. Fletcher, S. Karunananthan, K. BandeenRoche, F. Béland, H. Bergman, Correspondence analysis is a useful tool to uncover the relationships among categorical variables, J. Clin. Epidemiol. 63 (2010) 638-646. doi:10.1016/j.jclinepi.2009.08.008.

[41] C.J. Lorenzen, A method for the continuous measurement of in vivo chlorophyll concentration, in: Deep Sea Res. Oceanogr. Abstr., Elsevier, 1966: pp. 223-227. http://www.sciencedirect.com/science/article/pii/0011747166911028 (accessed October 10, 2017).

[42] G. Chen, Y. Jiang, F. Chen, Fatty acid and lipid class composition of the eicosapentaenoic acid-producing microalga, Nitzschia laevis, Food Chem. 104 (2007) 1580-1585. doi:10.1016/j.foodchem.2007.03.008.

[43] M.C. Dalay, S.S. Gunes, others, Biodiesel from Microalgae: A Renewable Energy Source, Middle East J. Sci. Res. 22 (2014) 350-355. http://idosi.org/mejsr/mejsr21(12)14/15.pdf (accessed February 19, 2016).

[44] M.J. Griffiths, S.T.L. Harrison, Lipid productivity as a key characteristic for choosing algal species for biodiesel production, J. Appl. Phycol. 21 (2009) 493-507. doi:10.1007/s10811-008-9392-7.

[45] J. Johansen, P. Lemke, N. Nagle, P. Chelf, P. Roessler, R. Galloway, S. Toon, Addendum to Microalgae Culture Collection 1986-1987, National Renewable Energy Lab.(NREL), Golden, CO (United States), 1987.

[46] S.M. Renaud, L.-V. Thinh, D.L. Parry, The gross chemical composition and fatty acid composition of 18 species of tropical Australian microalgae for possible use in mariculture, Aquaculture. 170 (1999) 147-159.

[47] J. Sheehan, T. Dunahay, J. Benemann, P. Roessler, Look Back at the U.S. Department of Energy's Aquatic Species Program: Biodiesel from Algae; Close-Out Report, National Renewable Energy Lab., Golden, CO. (US), 1998. doi:10.2172/15003040.

[48] Z.-Y. Wen, F. Chen, Production potential of eicosapentaenoic acid by the diatom Nitzschia laevis, Biotechnol. Lett. 22 (2000) 727-733. http://link.springer.com/article/10.1023/A:1005666219163 (accessed February 18, 2016). 
982

983

984

985

986

987

988

989

990

991

992

993

994

995

996

997

998

999

1000

1001

1002

1003

[49] F.-Y. Zhao, J.-R. Liang, Y.-H. Gao, Q.-Q. Luo, Y. Yu, C.-P. Chen, L. Sun, Variations in the Total Lipid Content and Biological Characteristics of Diatom Species for Potential Biodiesel Production, J. Fundam. Renew. Energy Appl. 2016 (2016). http://www.omicsonline.com/open-access/variations-in-the-total-lipid-content-andbiological-characteristics-of-diatom-species-for-potential-biodiesel-production-20904541-1000201.php?aid=66659 (accessed February 9, 2016).

[50] T. Jauffrais, S. Drouet, V. Turpin, V. Méléder, B. Jesus, B. Cognie, P. Raimbault, R.P. Cosson, P. Decottignies, V. Martin-Jézéquel, Growth and biochemical composition of a microphytobenthic diatom (Entomoneis paludosa) exposed to shorebird (Calidris alpina) droppings, J. Exp. Mar. Biol. Ecol. 469 (2015) 83-92.

[51] T. Jauffrais, B. Jesus, V. Méléder, V. Turpin, A.D.P.G. Russo, P. Raimbault, V.M. Jézéquel, Physiological and photophysiological responses of the benthic diatom Entomoneis paludosa (Bacillariophyceae) to dissolved inorganic and organic nitrogen in culture, Mar. Biol. 163 (2016). doi:10.1007/s00227-016-2888-9.

[52] R.M. Knuckey, M.R. Brown, S.M. Barrett, G.M. Hallegraeff, Isolation of new nanoplanktonic diatom strains and their evaluation as diets for juvenile Pacific oysters $\begin{array}{lllll}\text { (Crassostrea } & \text { gigas), } & \text { Aquaculture. } & 211 & \text { (2002) }\end{array}$ doi:http://dx.doi.org/10.1016/S0044-8486(02)00010-8.

[53] A.T. Soares, B.F. Silva, L.L. Fialho, M.A.G. Pequeno, A.A.H. Vieira, A.G. Souza, N.R. Antoniosi Filho, Chromatographic characterization of triacylglycerides and fatty acid methyl esters in microalgae oils for biodiesel production, J. Renew. Sustain. Energy. 5 (2013) 053111. doi:10.1063/1.4821289.

[54] T. Viriyayingsiri, P. Sittplangkoon, S. Powtongsook, K. Nootong, Continuous production of diatom Entomoneis sp. in mechanically stirred tank and flat-panel airlift photobioreactors, Prep. Biochem. Biotechnol. $46 \quad$ (2016) 740-746. doi:10.1080/10826068.2015.1135460.

[55] F.J. Fields, J.P. Kociolek, An evolutionary perspective on selecting high-lipid-content diatoms (Bacillariophyta), J. Appl. Phycol. 27 (2015) 2209-2220. doi:10.1007/s10811014-0505-1.

[56] G.E. Fogg, D.M. Collyer, The accumulation of fats as a characteristic of certain classes of algae, Proc 8 Int Bot Congr. 17 (1954) 28.

[57] P.G. Roessler, ENVIRONMENTAL CONTROL OF GLYCEROLIPID METABOLISM IN MICROALGAE: COMMERCIAL IMPLICATIONS AND FUTURE RESEARCH DIRECTIONS, J. Phycol. $26 \quad$ (1990) 393-399. doi:10.1111/j.0022-3646.1990.00393.x.

[58] B. Scholz, G. Liebezeit, Biochemical characterisation and fatty acid profiles of 25 benthic marine diatoms isolated from the Solthörn tidal flat (southern North Sea), J. Appl. Phycol. 25 (2013) 453-465. doi:10.1007/s10811-012-9879-0.

[59] M. Islam, M. Magnusson, R. Brown, G. Ayoko, M. Nabi, K. Heimann, Microalgal Species Selection for Biodiesel Production Based on Fuel Properties Derived from Fatty Acid Profiles, Energies. 6 (2013) 5676-5702. doi:10.3390/en6115676.

[60] S.P. Slocombe, Q. Zhang, M. Ross, A. Anderson, N.J. Thomas, Á. Lapresa, C. RadMenéndez, C.N. Campbell, K.D. Black, M.S. Stanley, Unlocking nature's treasurechest: screening for oleaginous algae, Sci. Rep. 5 (2015) 9844.

[61] H. Chtourou, I. Dahmen, A. Jebali, F. Karray, I. Hassairi, S. Abdelkafi, H. Ayadi, S. Sayadi, A. Dhouib, Characterization of Amphora sp., a newly isolated diatom wild strain, potentially usable for biodiesel production, Bioprocess Biosyst. Eng. 38 (2015) 1381-1392. doi:10.1007/s00449-015-1379-6. 
[62] M. De la Pena, Cell growth and nutritive value of the tropical benthic diatom, Amphora sp., at varying levels of nutrients and light intensity, and different culture locations, J. Appl. Phycol. 19 (2007) 647-655.

[63] M. Giordano, M. Kansiz, P. Heraud, J. Beardall, B. Wood, D. McNaughton, Fourier transform infrared spectroscopy as a novel tool to investigate changes in intracellular macromolecular pools in the marine microalga Chaetoceros muellerii (Bacillariophyceae), J. Phycol. 37 (2001) 271-279.

[64] H. Wagner, S. Dunker, Z. Liu, C. Wilhelm, Subcommunity FTIR-spectroscopy to determine physiological cell states, Curr. Opin. Biotechnol. 24 (2013) 88-94. doi:https://doi.org/10.1016/j.copbio.2012.09.008.

[65] L.E. Brand, R.R. Guillard, L.S. Murphy, A method for the rapid and precise determination of acclimated phytoplankton reproduction rates, J. Plankton Res. 3 (1981) 193-201. http://plankt.oxfordjournals.org/content/3/2/193.short (accessed April 5, 2016).

[66] M. Gilstad, E. Sakshaug, Growth rates of ten diatom species from the Barents Sea at different irradiances and day lengths., Mar. Ecol. Prog. Ser. Oldendorf. 64 (1990) 169173.

[67] C. Breil, M. Abert Vian, T. Zemb, W. Kunz, F. Chemat, "Bligh and Dyer" and Folch Methods for Solid-Liquid-Liquid Extraction of Lipids from Microorganisms. Comprehension of Solvatation Mechanisms and towards Substitution with Alternative Solvents, Int. J. Mol. Sci. 18 (2017). doi:10.3390/ijms18040708.

[68] G.-D. Feng, F. Zhang, L.-H. Cheng, X.-H. Xu, L. Zhang, H.-L. Chen, Evaluation of FTIR and Nile Red methods for microalgal lipid characterization and biomass composition determination, Bioresour. Technol. 128 (2013) 107-112.

[69] K. Stehfest, J. Toepel, C. Wilhelm, The application of micro-FTIR spectroscopy to analyze nutrient stress-related changes in biomass composition of phytoplankton algae, Plant Physiol. Biochem. 43 (2005) 717-726. doi:10.1016/j.plaphy.2005.07.001.

[70] A.P. Dean, D.C. Sigee, B. Estrada, J.K. Pittman, Using FTIR spectroscopy for rapid determination of lipid accumulation in response to nitrogen limitation in freshwater $\begin{array}{lllll}\text { microalgae, } & \text { Bioresour. } & \text { Technol. } & 101 & \text { (2010) 4499-4507. }\end{array}$ doi:10.1016/j.biortech.2010.01.065.

[71] M. Mubarak, A. Shaija, T.V. Suchithra, A review on the extraction of lipid from microalgae for biodiesel production, Algal Res. 7 (2015) 117-123. doi:10.1016/j.algal.2014.10.008.

[72] Y. Li, F.G. Naghdi, S. Garg, T.C. Adarme-Vega, K.J. Thurecht, W.A. Ghafor, S. Tannock, P.M. Schenk, A comparative study: the impact of different lipid extraction methods on current microalgal lipid research, Microb. Cell Factories. 13 (2014) 14.

[73] S.J. Lee, B.-D. Yoon, H.-M. Oh, Rapid method for the determination of lipid from the green alga Botryococcus braunii, Biotechnol. Tech. 12 (1998) 553-556.

[74] D. Xu, Z. Gao, F. Li, X. Fan, X. Zhang, N. Ye, S. Mou, C. Liang, D. Li, Detection and quantitation of lipid in the microalga Tetraselmis subcordiformis (Wille) Butcher with BODIPY 505/515 staining, Bioresour. Technol. 127 (2013) 386-390. doi:10.1016/j.biortech.2012.09.068.

[75] H. De la Hoz Siegler, W. Ayidzoe, A. Ben-Zvi, R. Burrell, W. McCaffrey, Improving the reliability of fluorescence-based neutral lipid content measurements in microalgal cultures, Algal Res. 1 (2012) 176-184.

[76] T. Mutanda, D. Ramesh, S. Karthikeyan, S. Kumari, A. Anandraj, F. Bux, Bioprospecting for hyper-lipid producing microalgal strains for sustainable biofuel production, Bioresour. Technol. 102 (2011) 57-70. doi:10.1016/j.biortech.2010.06.077. 
[77] W. Chen, C. Zhang, L. Song, M. Sommerfeld, Q. Hu, A high throughput Nile red method for quantitative measurement of neutral lipids in microalgae, J. Microbiol. Methods. 77 (2009) 41-47. doi:10.1016/j.mimet.2009.01.001.

[78] L.M. Laurens, E.J. Wolfrum, Rapid compositional analysis of microalgae by NIR spectroscopy, NIR News. 23 (2012) 9-11.

[79] M.S. Cooper, W.R. Hardin, T.W. Petersen, R.A. Cattolico, Visualizing "green oil" in live algal cells, J. Biosci. Bioeng. $109 \quad$ (2010) 198-201. doi:10.1016/j.jbiosc.2009.08.004.

[80] J.N. Murdock, D.L. Wetzel, FT-IR Microspectroscopy Enhances Biological and Ecological Analysis of Algae, Appl. Spectrosc. Rev. 44 (2009) 335-361. doi:10.1080/05704920902907440.

[81] I. Dreissig, S. Machill, R. Salzer, C. Krafft, Quantification of brain lipids by FTIR spectroscopy and partial least squares regression, Spectrochim. Acta. A. Mol. Biomol. Spectrosc. 71 (2009) 2069-2075. doi:10.1016/j.saa.2008.08.008.

[82] S.M. Renaud, H.C. Zhou, D.L. Parry, L.-V. Thinh, K.C. Woo, Effect of temperature on the growth, total lipid content and fatty acid composition of recently isolated tropical microalgae Isochrysis sp., Nitzschia closterium, Nitzschia paleacea, and commercial species Isochrysis sp.(clone T. ISO), J. Appl. Phycol. 7 (1995) 595-602. http://link.springer.com/article/10.1007/BF00003948 (accessed August 25, 2016).

[83] M.A. Borowitzka, L.J. Borowitzka, Micro-algal biotechnology, Cambridge University Press, 1988.

[84] H.A. Spoehr, H.W. Milner, THE CHEMICAL COMPOSITION OF CHLORELLA; EFFECT OF ENVIRONMENTAL CONDITIONS, Plant Physiol. 24 (1949) 120-149. https://www.ncbi.nlm.nih.gov/pmc/articles/PMC437916/.

[85] I.A. Guschina, J.L. Harwood, Lipids and lipid metabolism in eukaryotic algae, Prog. Lipid Res. 45 (2006) 160-186. doi:10.1016/j.plipres.2006.01.001.

[86] L. Brand, R. Guillard, The effects of continuous light and light intensity on the reproduction rates of twenty-two species of marine phytoplankton, J. Exp. Mar. Biol. Ecol. 50 (1981) 119-132.

[87] P.J. le B. Williams, L.M. Laurens, Microalgae as biodiesel \& biomass feedstocks: review $\&$ analysis of the biochemistry, energetics \& economics, Energy Environ. Sci. 3 (2010) 554-590.

[88] S. Wahidin, A. Idris, S.R.M. Shaleh, The influence of light intensity and photoperiod on the growth and lipid content of microalgae Nannochloropsis sp., Bioresour. Technol. 129 (2013) 7-11. doi:10/f4mb36.

[89] L. Rodolfi, G. Chini Zittelli, N. Bassi, G. Padovani, N. Biondi, G. Bonini, M.R. Tredici, Microalgae for oil: Strain selection, induction of lipid synthesis and outdoor mass cultivation in a low-cost photobioreactor, Biotechnol. Bioeng. 102 (2009) 100-112. doi:10.1002/bit.22033.

[90] E.S. Shuba, D. Kifle, Microalgae to biofuels: 'Promising' alternative and renewable energy, review, Renew. Sustain. Energy Rev. 81 (2018) 743-755. doi:10.1016/j.rser.2017.08.042.

[91] M.P. de Souza, M. Hoeltz, P.D. Gressler, L.B. Benitez, R.C.S. Schneider, Potential of Microalgal Bioproducts: General Perspectives and Main Challenges, Waste Biomass Valorization. (2018). doi:10.1007/s12649-018-0253-6.

[92] M.-H. Liang, J. Zhu, J.-G. Jiang, High-value bioproducts from microalgae: strategies and progress, Crit. Rev. Food Sci. Nutr. 0 (2018) 01-53. doi:10.1080/10408398.2018.1455030. 


\section{Figure legends}

1106 Figure. 1 Example of growth curves measured for Amphora sp 1 NCC260 by (A) cell count, 1107 (B) fluorometry PAM (F0) and (C) radiometry (NDVI). Points corresponding to cell 1108 concentration according to time. Line curves corresponding to the Gompertz model fitted to 1109 cell concentration as a function of time. $n=3$, vertical bar $=$ SD. The arrows indicate the late 1110 exponential day estimated by the Gompertz model.

1111 Figure. 2 Values of the parameters measured for the screened strains. This includes strain 1112 productivity (A), lipid content as measured from the gravimetric method (B), the lipid ratio as 1113 measured semi-quantitatively by the FTIR approaches, [(eb+CH3+CH3)/si] (C) or [area $1114 \mathrm{eb}+\mathrm{CH} 2+\mathrm{CH} 3) /$ Total area] multiplied by 100 for scaling purposes (D). The $\mathrm{a}, \mathrm{b}$, c notation 1115 corresponded to the maximum and minimum values for groups 1,2 and $3 . \mathrm{N}=3$, independent 1116 measurements, \pm SD.

1117 Figure. 3 Example of averaged FTIR spectra recorded on entire cells or on the corresponding 1118 lipid extract. (A) Staurosira sp NCC182 FTIR signature recorded on the entire cells and (B)

1119 Staurosira sp NCC182 FTIR signature recorded on a crude lipid extract. The grey area 1120 corresponds to the variation of the FTIR signal associated to the standard deviation for $n=3$ 1121 independent measurements.

1122 Figure. 4 Correspondence analysis map calculated on the basis of the macromolecular content 1123 as evaluated by FTIR on all the assayed strains of the NCC. N=3 independent measurements.

1124 Figure 5 Venn diagram showing the degree of overlap among the different approaches used 1125 to identify the lipid rich diatoms. In the gravimetric method circle, 14 strains were identified 1126 as rich in lipids: 4 only with this method (NCC260, NCC208, NCC253, NCC351), one strains 1127 were also identified as rich and lipid by the FTIR on lipid extract (NCC229), and two strains 1128 were also identified as rich in lipids by the FTIR on entire cells (NCC33, NCC199). One strain 1129 was identified by FTIR on lipid extract and FTIR on whole cells (NCC366) and seven strains 1130 were identified as rich in lipids by all three methods (NCC109, NCC182, NCC113, NCC270, 1131 NCC169, NCC303, NCC216). 
1132 Figure 6. Boxplots summarizing the sample distribution criteria as measured with FTIR

1133 methods, gravimetry for the lipid rate and with flurorimetry for productivity. FTIR data was

1134 expressed in arbitrary units. Lipid rates in \%DW and Px in g.L L $^{-1}$ day $^{-1}$ FTIR results

1135 wasmultiplied by 20 for scaling purposes. The Px was multiplied by 100 for scaling purposes.

113633 strains were assayed in independent biological triplicates.

1137

1138

1139

1140 Figures

1141

1142 Figure 1.

1143
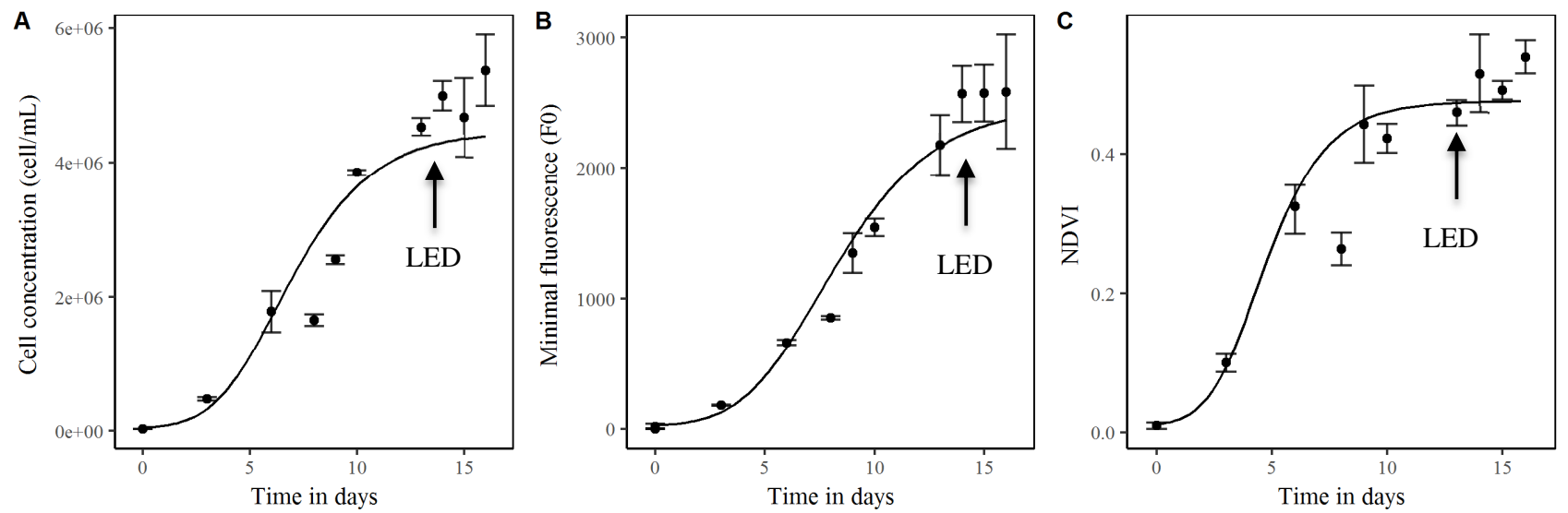

1144

1145

1146

1147

1148

1149

1150

1151

1152 


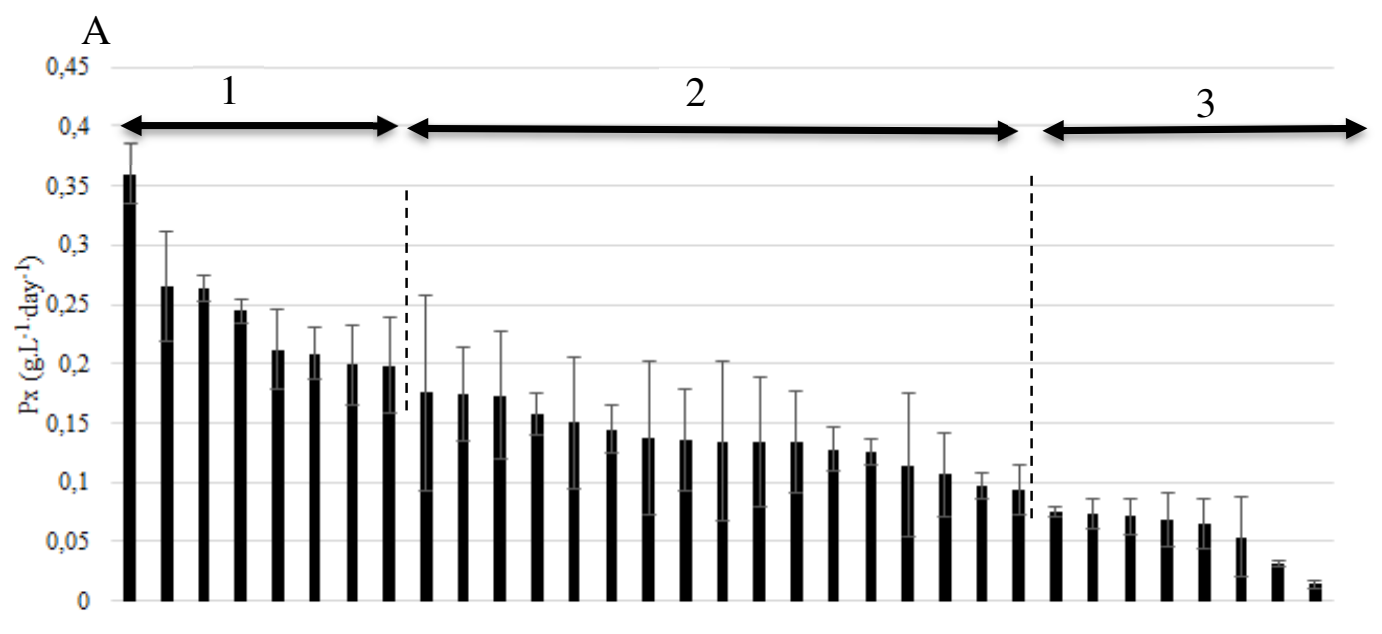

B
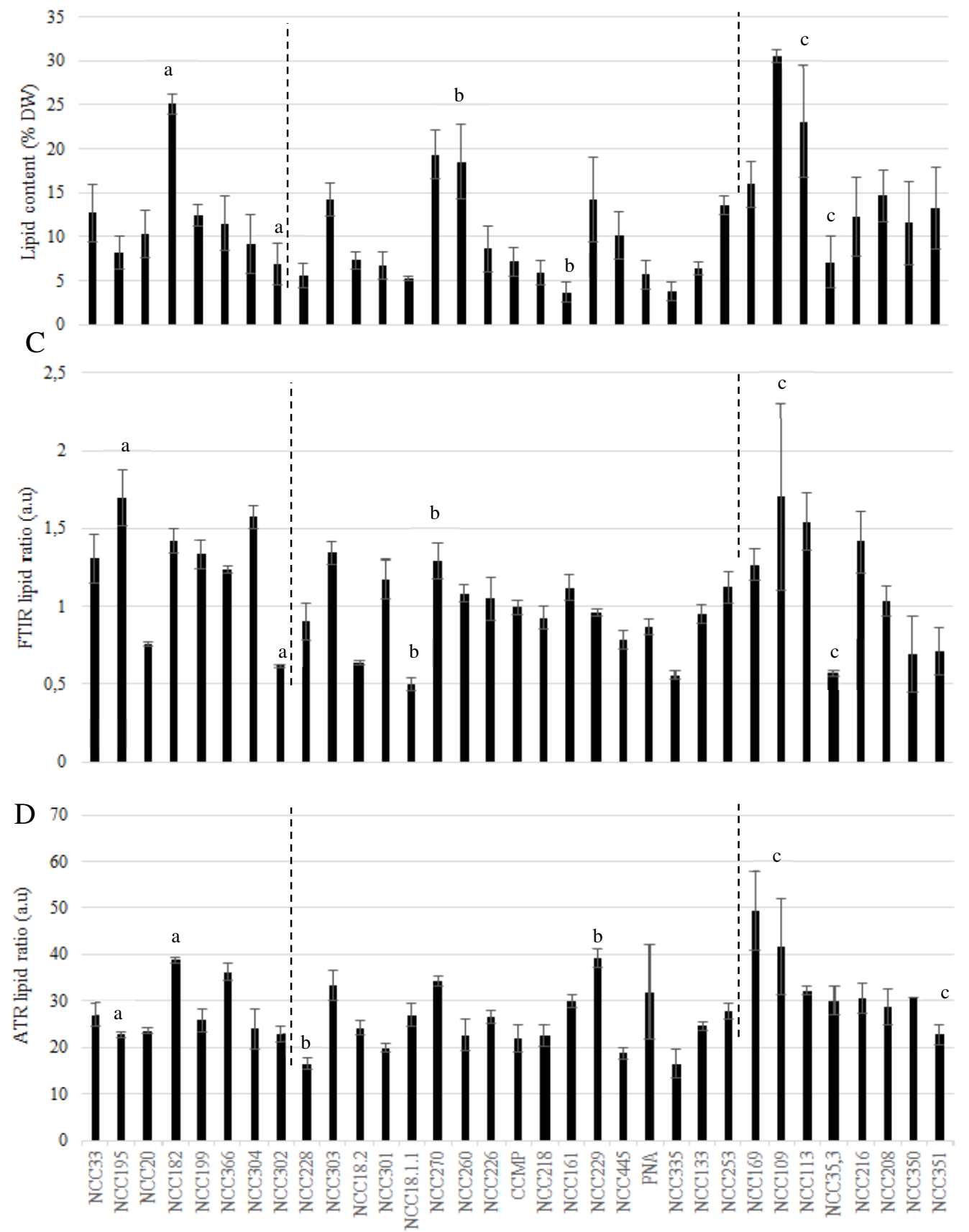
1154

1155 Fig. 3

1156

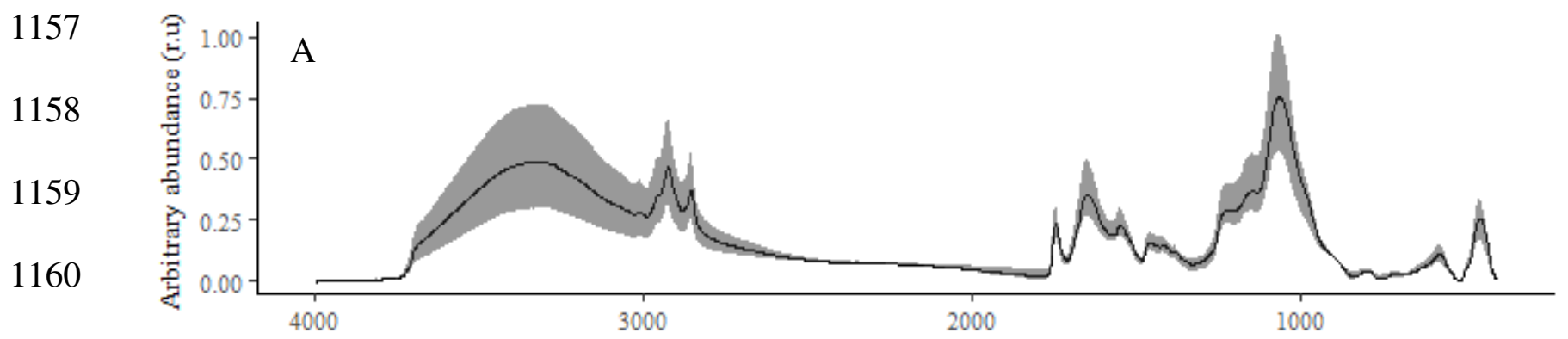

1161

Wavelenght $\left(\mathrm{cm}^{-1}\right)$

1162

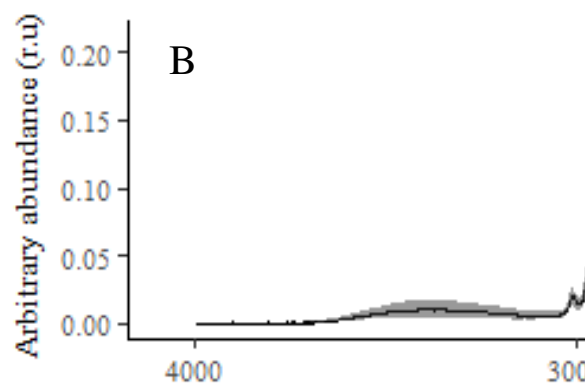

1166
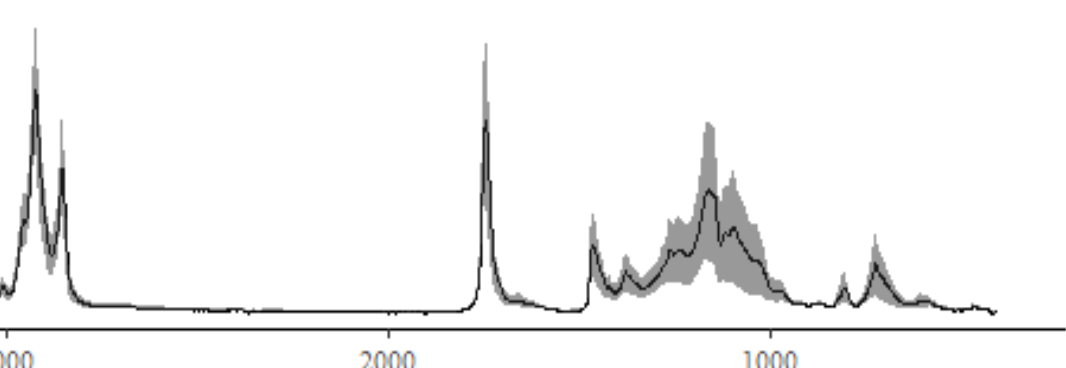

Wavelenght $\left(\mathrm{cm}^{-1}\right)$

1167

1168

1169

1170

1171

1172

1173

1174

1175

1176

1177

1178 
$1179 \quad$ Fig. 4

1180

1181

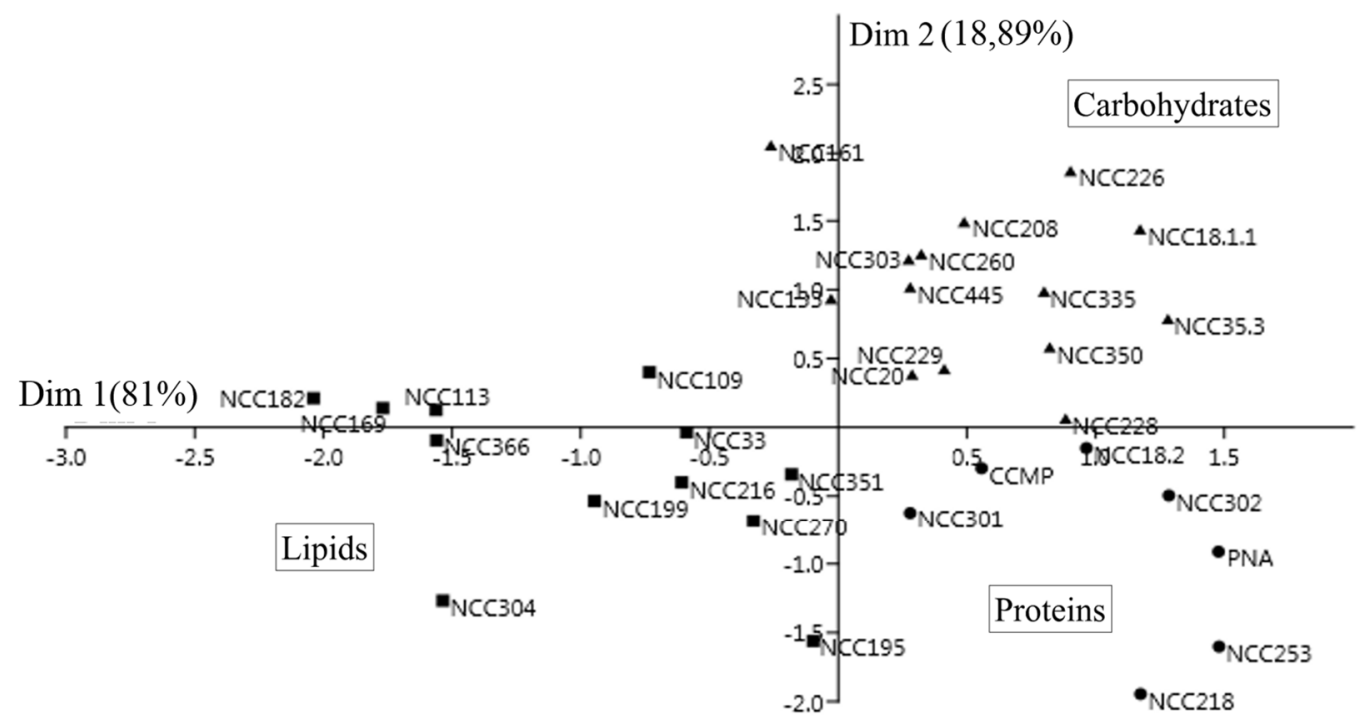

1182

1183

1184

1185

1186

1187

1188

1189

1190

1191

1192

1193

1194 
1195 Fig. 5

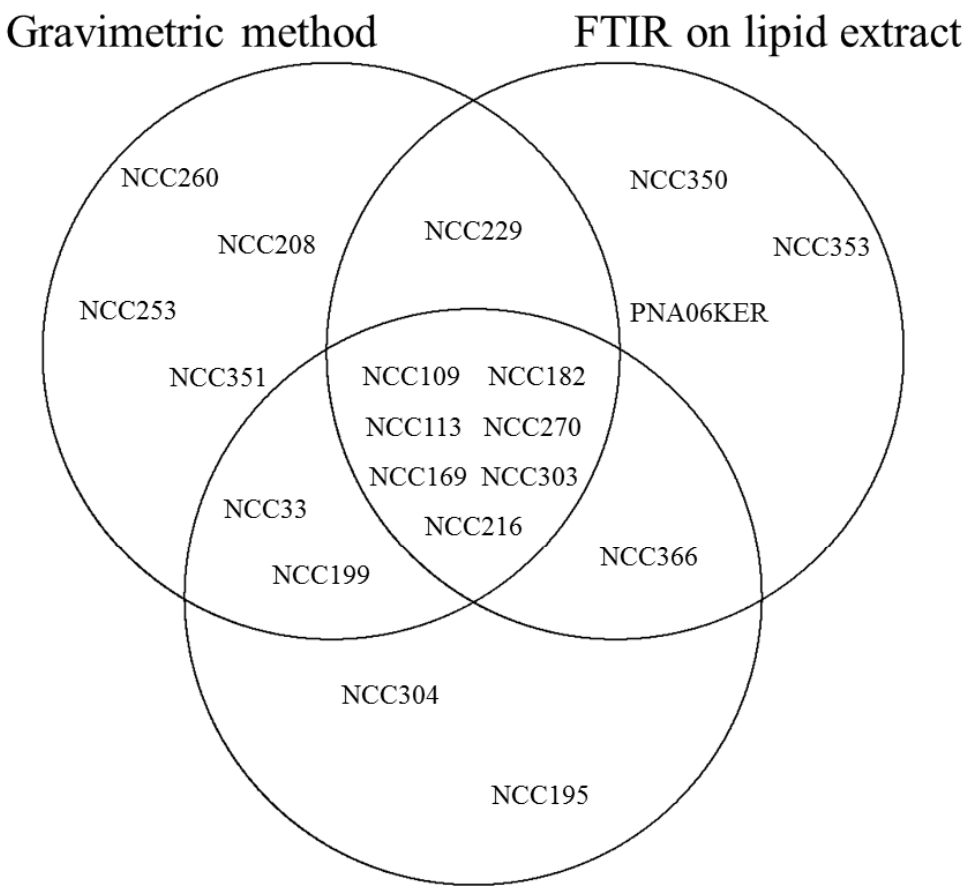

FTIR on entire cells

1196

1197

1198

1199

1200

1201

1202

1203

1204

1205

1206

1207

1208 
$1210 \quad$ Fig. 6

1211

1212

1213

1214

1215

1216

1217

1218

1219

1220

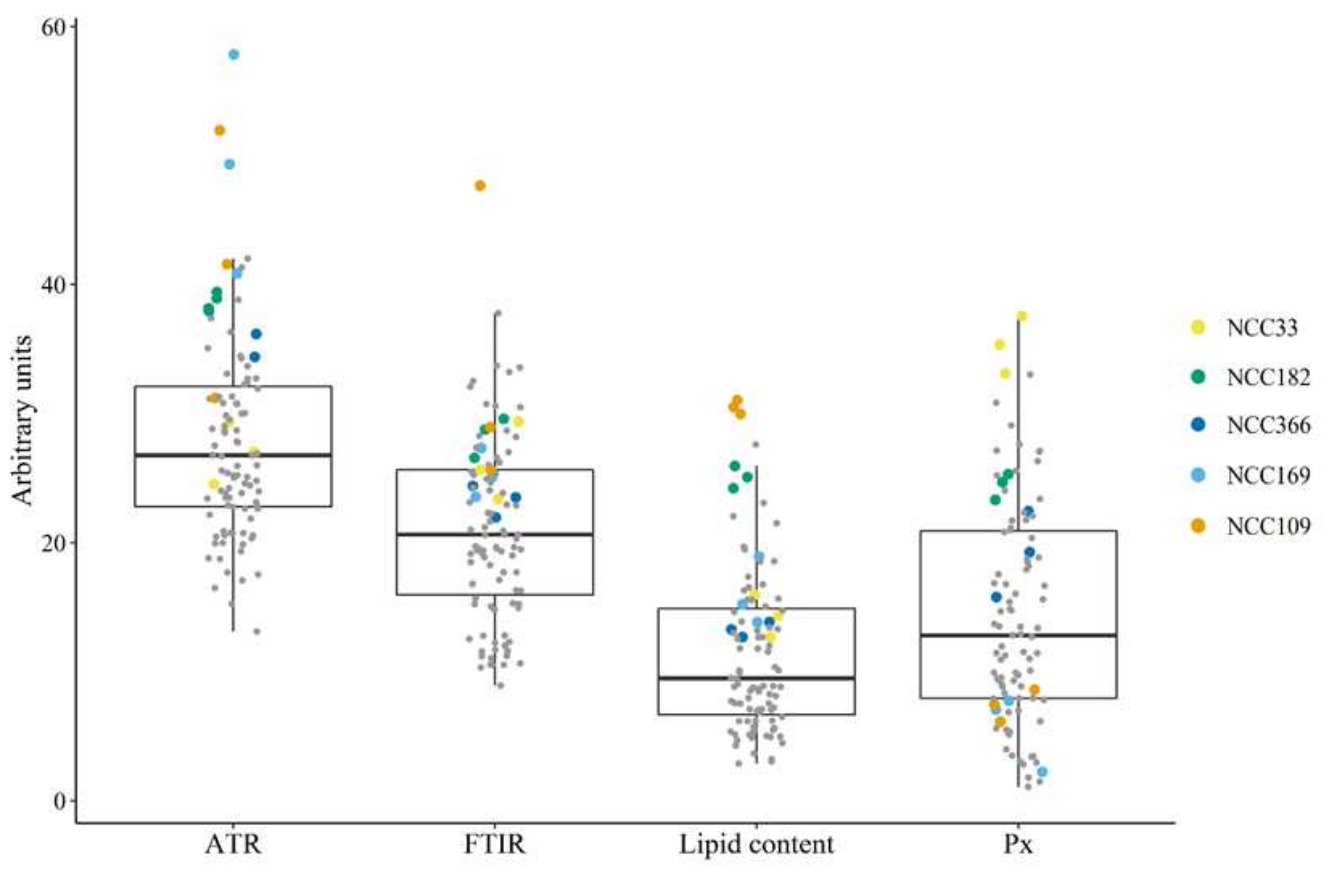

1221

1222

1223

1224

1225

1226

1227

1228

1229

1230

1231

1232

1233 
1235 Table S1. Supplementary data. Strains who did not grown.

1236

1237

1238

1239

1240

1241

1242

1243

\begin{tabular}{|c|c|c|}
\hline Species & $\begin{array}{l}\text { NCC strain } \\
\text { identification }\end{array}$ & Sampling location \\
\hline Amphora sp. B2 & NCC261 & France, $N W$ Atlantic coast \\
\hline Amphora sp. AC16 & NCC410 & France, $N W$ Atlantic coast \\
\hline Amphora sp. AE8 & NCC413 & France, $N W$ Atlantic coast \\
\hline Berkeleya rutilans & NCC210.2 & France, $N W$ Atlantic coast \\
\hline Berkeleya rutilans & NCC309 & France, Mediterranean sea \\
\hline Brockmaniella brockmanii 2 & NCC403 & France, $N W$ Atlantic coast \\
\hline Caloneis sp. 1 & NCC 180 & France, $N W$ Atlantic coast \\
\hline Catacombas sp. 1 & NCC337 & France, Mediterranean sea \\
\hline Cocconeis scutellum 1 & NCC209.1 & France, $N W$ Atlantic coast \\
\hline Cocconeis scutellum 2 & NCC209.2 & France, NW Atlantic coast \\
\hline Cocconeis scutellum 2 & NCC209.3 & France, NW Atlantic coast \\
\hline Craspedostauros sp. 3 & NCC57 & France, $N W$ Atlantic coast \\
\hline Craspedostauros sp. 4 & NCC58 & France, $N W$ Atlantic coast \\
\hline Craspedostauros sp. 5 & $\mathrm{NCC} 204$ & France, $N W$ Atlantic coast \\
\hline Entomoneis alata 1 & NCC16 & France, $N W$ Atlantic coast \\
\hline Entomoneis alata 2 & NCC448 & Portugal, NW Atlantic coast \\
\hline Entomoneis sp. BAB2 & NCC415 & France, NW Atlantic coast \\
\hline Gyrosigma sp. 1 & NCC411 & France, NW Atlantic coast \\
\hline Gyrosigma sp. 2 & $\mathrm{NCC} 412$ & France, $N W$ Atlantic coast \\
\hline Gyrosigma tenuissimum & NCC258 & France, $N W$ Atlantic coast \\
\hline Halamphora coffeaformis & UTCC58 & Canada, NW Atlantic coast \\
\hline Helicotheca tamesis 1 & NCC59 & , France, Mediterranean sea \\
\hline Helicotheca tamesis 2 & NCC60 & France, $N W$ Atlantic coast \\
\hline Lampriscus sp. & NCC347 & France, Mediterranean sea \\
\hline Leptocylindrus danicus 1 & NCC205 & France, $N W$ Atlantic coast \\
\hline Leptocylindrus danicus 2 & NCC206 & France,NW Atlantic coast \\
\hline Melosira nummuloîdes 1 & $\mathrm{NCC} 25$ & France, $N W$ Atlantic coast \\
\hline Melosira nummuloîdes 2 & NCC25.1 & France, $N W$ Atlantic coast \\
\hline Navicula sp. Z4 & $\mathrm{NCC} 224$ & France,NW Atlantic coast \\
\hline Navicula sp. e1 & NCC269 & France, $N W$ Atlantic coast \\
\hline Navicula cf ramosissima & NCC449 & France, $N W$ Atlantic coast \\
\hline Nitzschia laevis & NCC39 & France, $N W$ Atlantic coast \\
\hline Nitzschia salinicola & NCC41 & France, $N W$ Atlantic coast \\
\hline Nitzschia sp. B4 & NCC114 & France, $N W$ Atlantic coast \\
\hline Opehora sp. 2 & $\mathrm{NCC} 365$ & France, $N W$ Atlantic coast \\
\hline Paralia sulcata & NCC177 & France, $N W$ Atlantic coast \\
\hline Pleurosigma sp. K & NCC339 & Ukraine, Black sea \\
\hline Pleurosigma sp. LM & $\mathrm{NCC} 404$ & France, $N W$ Atlantic coast \\
\hline Pleurosigma sp. BC1 & $\mathrm{NCC} 423$ & France, $N W$ Atlantic coast \\
\hline Pleurosigma sp. BC7 & $\mathrm{NCC} 425$ & France, $N W$ Atlantic coast \\
\hline Pleurosigma sp. BC15 & $\mathrm{NCC} 428$ & France, $N W$ Atlantic coast \\
\hline Rhizosolenia setigera & $\mathrm{NCC} 127$ & France, $N W$ Atlantic coast \\
\hline Tabularia tabulata & NCC338 & France, $N W$ Atlantic coast \\
\hline
\end{tabular}


Table S2: Lipid quantification evaluated by FTIR and ATR method for all the species.

\begin{tabular}{|c|c|c|c|c|c|c|c|c|}
\hline \multirow{2}{*}{ Species } & \multirow{2}{*}{ code } & \multicolumn{5}{|c|}{ FTIR } & \multicolumn{2}{|c|}{ ATR } \\
\hline & & Carb/si & Prot/si & $\mathrm{Eb} / \mathrm{si}$ & $\mathrm{CH} 2 / \mathrm{si}$ & $\mathrm{CH} 3 / \mathrm{si}$ & eb & $\mathrm{CH} 2+\mathrm{CH} 3$ \\
\hline Amphora acutiuscula & NCC216 & $53.6 \pm 8.2$ & $45.8 \pm 5.7$ & $22.1 \pm 4.9$ & $65.7 \pm 8.0$ & $53.5 \pm 7.8$ & $6.2 \pm 0.9$ & $24.3 \pm 2.4$ \\
\hline Amphora sp. 1 & NCC260 & $63.6 \pm 2.9$ & $40.0 \pm 2.0$ & $12.2 \pm 2.3$ & $57.3 \pm 3.3$ & $39.2 \pm 0.6$ & $4.5 \pm 0.7$ & $18.1 \pm 3.1$ \\
\hline Amphora sp. 2 & NCC169 & $58.1 \pm 4.3$ & $42.4 \pm 1.1$ & $17.2 \pm 3.4$ & $59.7 \pm 3.4$ & $49.7 \pm 3.0$ & $7.1 \pm 0.7$ & $42.1 \pm 11.0$ \\
\hline Brockmaniella brockmanii & NCC161 & $51.2 \pm 5.5$ & $25.2 \pm 6.4$ & $12.8 \pm 4.0$ & $57.7 \pm 5.5$ & $41.8 \pm 5.5$ & $4.1 \pm 1.6$ & $21.1 \pm 5.6$ \\
\hline Conticriba weissflogii & NCC133 & $47.4 \pm 0.5$ & $40.2 \pm 0.8$ & $5.03 \pm 1.5$ & $48.4 \pm 2.6$ & $41.7 \pm 1.9$ & $4.7 \pm 0.3$ & $20.0 \pm 0.7$ \\
\hline Conticriba weissflogii & CCMP1336 & $48.3 \pm 2.8$ & $43.5 \pm 3.3$ & $9.8 \pm 1.8$ & $48.7 \pm 3.0$ & $40.9 \pm 2.7$ & $5.0 \pm 0.7$ & $16.9 \pm 2.2$ \\
\hline Craspedostauros britannicus & NCC195 & $60.7 \pm 2.4$ & $69.8 \pm 11$ & $23.2 \pm 3.3$ & $80.7 \pm 8.0$ & $66.0 \pm 6.9$ & $4.8 \pm 0.4$ & $19.2 \pm 1.8$ \\
\hline Craspedostauros britannicus & NCC199 & $55.1 \pm 3.4$ & $47.5 \pm 5.7$ & $26.9 \pm 3.4$ & $62.2 \pm 2.7$ & $44.2 \pm 3.3$ & $5.4 \pm 0.6$ & $20.5 \pm 1.9$ \\
\hline Craspedostauros sp. 1 & NCC228 & $44.3 \pm 0.1$ & $37.8 \pm 4.3$ & $6.2 \pm 0.4$ & $46.3 \pm 6.4$ & $37.8 \pm 6.0$ & $3.9 \pm 0.8$ & $15.2 \pm 3.4$ \\
\hline Craspedostauros sp. 2 & $\mathrm{NCC} 218$ & $54.6 \pm 2.6$ & $49.4 \pm 3.5$ & $7.5 \pm 0.3$ & $46.0 \pm 3.8$ & $39.0 \pm 4.0$ & $4.7 \pm 0.3$ & $17.9 \pm 2.5$ \\
\hline Cymatosira belgica & NCC208 & $41.6 \pm 4.8$ & $25.4 \pm 3.3$ & $6.7 \pm 1.1$ & $55.4 \pm 5.1$ & $41.5 \pm 3.7$ & $5.9 \pm 0.7$ & $22.7 \pm 3.2$ \\
\hline Entomoneis paludosa & NCC18.1.1 & $39.6 \pm 0.3$ & $26.0 \pm 2.7$ & $2.9 \pm 0.1$ & $27.3 \pm 2.4$ & $19.4 \pm 1.8$ & $3.9 \pm 0.7$ & $23.1 \pm 1.8$ \\
\hline Entomoneis paludosa & NCC18.2.1 & $45.7 \pm 0.6$ & $40.9 \pm 1.4$ & $6.1 \pm 0.1$ & $34.5 \pm 0.9$ & $22.5 \pm 0.6$ & $3.1 \pm 0.4$ & $21.6 \pm 1.1$ \\
\hline Entomoneis sp. 1 & NCC350 & $39.9 \pm 0.1$ & $30.4 \pm 0.8$ & $5.5 \pm 1.5$ & $28.6 \pm 0.9$ & $21.2 \pm 1.7$ & $2.7 \pm 0.1$ & $30.6 \pm 4.3$ \\
\hline Entomoneis sp. 2 & NCC20 & $42.5 \pm 0.5$ & $32.5 \pm 0.3$ & $9.5 \pm 0.3$ & $40.0 \pm 0.4$ & $26.0 \pm 0.6$ & $4.7 \pm 0.3$ & $18 . .6 \pm 0.4$ \\
\hline Entomoneis sp. 3 & NCC351 & $45.5 \pm 2.9$ & $41.4 \pm 4.2$ & $14.4 \pm 3.4$ & $37.2 \pm 0.8$ & $28.3 \pm 0.6$ & $3.9 \pm 1.7$ & $15.8 \pm 5.6$ \\
\hline Entomoneis sp. 4 & NCC301 & $62.5 \pm 4.8$ & $56.7 \pm 6.4$ & $12.5 \pm 2.5$ & $64.0 \pm 7.9$ & $46.7 \pm 5.6$ & $2.9 \pm 0.1$ & $17.0 \pm 0.8$ \\
\hline Entomoneis sp. 5 & NCC302 & $37.6 \pm 0.7$ & $36.8 \pm 0.8$ & $3.43 \pm 0.1$ & $33.9 \pm 0.7$ & $23.9 \pm 0.5$ & $3.3 \pm 0.3$ & $19.6 \pm 1.5$ \\
\hline Entomoneis sp. 6 & NCC335 & $50.5 \pm 0.6$ & $35.3 \pm 2.7$ & $6.6 \pm 0.7$ & $29.9 \pm 1.9$ & $19.0 \pm 1.1$ & $3.1 \pm 0.2$ & $13.4 \pm 3.0$ \\
\hline Entomoneis sp. 7 & NCC445 & $40.6 \pm 0.9$ & $27.0 \pm 2.7$ & $8.5 \pm 0.2$ & $37.7 \pm 0.4$ & $29.2 \pm 0.3$ & $4.1 \pm 0.9$ & $17.5 \pm 4.3$ \\
\hline Extubocellulus cf cribriger & NCC229 & $49.8 \pm 3.7$ & $38.1 \pm 2.6$ & $10.1 \pm 1.2$ & $48.0 \pm 1.9$ & $38.0 \pm 1.1$ & $4.9 \pm 0.3$ & $34.2 \pm 1.7$ \\
\hline Fallacia sp. 1 & NCC303 & $64.7 \pm 1.8$ & $74.4 \pm 7.0$ & $14.2 \pm 2.5$ & $64.5 \pm 4.1$ & $55.5 \pm 5.4$ & $6.9 \pm 0.3$ & $26.4 \pm 2.9$ \\
\hline Fallacia sp. 2 & NCC304 & $46.0 \pm 6.2$ & $45.7 \pm 3.2$ & $31.3 \pm 4.0$ & $72.8 \pm 2.7$ & $53.3 \pm 2.1$ & $5.1 \pm 1.0$ & $18.9 \pm 3.4$ \\
\hline Licmophora sp. 1 & NCC253 & $53.1 \pm 2.7$ & $65 \pm 10$ & $4.4 \pm 1.1$ & $57.9 \pm 5.4$ & $50.3 \pm 5.2$ & $3.6 \pm 0.3$ & $22.6 \pm 0.6$ \\
\hline Lithodesmium $s p$ & NCC353 & $34.2 \pm 2.0$ & $25.8 \pm 0.8$ & $2.4 \pm 0.3$ & $31.1 \pm 1.1$ & $23.1 \pm 0.4$ & $2.1 \pm 0.3$ & $28.0 \pm 3.2$ \\
\hline Navicula sp. 1 & NCC113 & $63.3 \pm 4.7$ & $43.8 \pm 8.9$ & $33.4 \pm 4.7$ & $68.2 \pm 9.6$ & $52.4 \pm 5.6$ & $3.4 \pm 0.4$ & $28.8 \pm 1.2$ \\
\hline Navicula sp. 2 & NCC226 & $54.2 \pm 4.3$ & $27.0 \pm 3.0$ & $5.2 \pm 0.9$ & $53.1 \pm 3.8$ & $39.5 \pm 2.8$ & $4.2 \pm 0.7$ & $22.4 \pm 0.7$ \\
\hline Nitzschia sp. 5 & NCC109 & $62.0 \pm 2.8$ & $42.4 \pm 6.7$ & $22.0 \pm 2.3$ & $72.7 \pm 4.6$ & $61.3 \pm 4.8$ & $6.9 \pm 0.4$ & $45.1 \pm 28.9$ \\
\hline Nitzschia alexandrina & NCC33 & $58.2 \pm 7.2$ & $44.0 \pm 4.6$ & $20.7 \pm 3.3$ & $56.1 \pm 4.0$ & $45.8 \pm 0.7$ & $5.7 \pm 0.3$ & $21.3 \pm 2.3$ \\
\hline Opephora sp. 1 & NCC366 & $58 \pm 12$ & $40.1 \pm 8.8$ & $31.6 \pm 6.1$ & $50.6 \pm 4.5$ & $42.0 \pm 2.5$ & $6.9 \pm 1.1$ & $26.3 \pm 4.4$ \\
\hline Pseudonitzschia americana & PNA06 KER & $56.6 \pm 1.4$ & $60.6 \pm 3.9$ & $3.9 \pm 1.0$ & $44.0 \pm 2.8$ & $39.1 \pm 3.2$ & $4.0 \pm 0.3$ & $38 \pm 28$ \\
\hline Staurosira sp. & NCC182 & $47.7 \pm 6.6$ & $30.7 \pm 4.1$ & $30.9 \pm 5.4$ & $61.6 \pm 4.0$ & $49.0 \pm 2.3$ & $7.3 \pm 0.1$ & $31.6 \pm 0.6$ \\
\hline Surirella sp. 1 & NCC270 & $58.5 \pm 2.4$ & $54.4 \pm 8.4$ & $22.0 \pm 4.6$ & $56.1 \pm 5.3$ & $51.3 \pm 5.4$ & $7.1 \pm 0.4$ & $27.1 \pm 0.6$ \\
\hline
\end{tabular}

